\title{
Emergence of collective digital innovations through the process of control point driven network reconfiguration and reframing: the case of mobile payment
}

\author{
Boriana Rukanova $^{1}$ (D) $\cdot$ Mark de Reuver $^{1} \cdot$ Stefan Henningsson ${ }^{2} \cdot$ Fatemeh Nikayin $^{1} \cdot$ Yao-Hua Tan $^{1}$
}

Received: 5 October 2018 / Accepted: 27 May 2019/Published online: 28 June 2019

(C) The Author(s) 2019

\begin{abstract}
Decentralized digital technologies require multiple organizations to collectively create digital innovations. Control over the resources required for digital innovations is often therefore dispersed among multiple actors. Actors may have conflicting interests and business models which cause collective digital innovations to come to a standstill. While existing research suggests various factors that block collective innovation processes, there is still little understanding of how organizations can overcome standstills, and progress to bringing digital innovations to market. The main question addressed in this paper is: How do collective digital innovation initiatives overcome standstills in order to progress in bringing the innovations to market? We offer a novel perspective on the process of developing collective digital innovations based on a longitudinal case study of mobile banking in the Netherlands. Our case shows how parties have collaborated to learn about new opportunities for distributing control and framing solutions, while the actual commercialization of the mobile payment solutions was performed by individual actors. The framework shows how digital innovations emerge through a series of collective innovation processes that build upon each other through control point driven network reconfiguration and reframing.
\end{abstract}

Keywords Mobile payment $\cdot$ Digital innovation $\cdot$ Collective action $\cdot$ Control points $\cdot$ Framing $\cdot$ Network mobilization

JEL classification $\mathrm{O} 31, \mathrm{O} 33 \cdot \mathrm{P} 13 \cdot \mathrm{L} 14, \mathrm{~L} 26$

\section{Introduction}

Responsible Editor: Charles Steinfield

Boriana Rukanova

b.d.rukanova@tudelft.nl

Mark de Reuver

G.A.deReuver@tudelft.nl

Stefan Henningsson

sh.itm@cbs.dk

Fatemeh Nikayin

fatemeh.nikayin@gmail.com

Yao-Hua Tan

Y.Tan@tudelft.nl

1 Faculty of Technology, Policy and Management, TU Delft, Building 31, Jaffalaan 5, 2628, BX Delft, The Netherlands

2 Copenhagen Business School, Frederiksberg, Denmark
Digitalization fuels innovation across a number of domains and the transformation of industries (Hess and Constantiou 2018). Digital innovation entails the use of digital or information technologies to create "novel products" (Yoo et al. 2010) or "a product, process, or business model that is perceived as new" (Fichman et al. 2014). Increasingly, digital innovation takes place within complex yet loosely coupled networks of organizations with distributed control (Yoo et al. 2012) over (digital) resources, which implies that decision rights are dispersed among various actors. Therefore, digital innovation can involve collaborative innovation, requiring the involvement of multiple actors. For instance, in the case of mobile payment innovations - the focus of this paper - resources are required from banks, payment service providers and telecom operators.

The notion that digital innovation requires resources from multiple actors dates back to early work on value networks (Allee 2000), in which organizations collaborate to offer a 
specific service or product (Peltoniemi and Vuori 2004). In this process, companies need also to be aware of the wider context, and it has been suggested that companies are likely to be more successful if they "run in packs" and engage in collective action rather than to go alone (Van de Ven 2005). Value networks change in the course of an incremental process of innovation, becoming more fluid and loosely coupled, ultimately even transforming into multisided markets (Pagani 2013). Governance of collaborative innovation in value networks requires formal and informal mechanisms (De Reuver and Bouwman 2012) as well as business models that incentivize each actor (Bouwman et al. 2008). In the stream of service innovation literature (see also Witell et al. 2015), it is similarly assumed that service offerings are created by recombining and 'liquifying' resources from an ecosystem of providers (Vargo and Lusch 2008; Vargo et al. 2008; Lusch and Nambisan 2015). Here, the term 'ecosystem' refers to actors who are bound together due to their non-generic complementarities (Jacobides et al. 2018). Digital platforms enable actors to mobilize and to access resources from the ecosystem (Storbacka et al. 2016), thus enabling exponential innovation while working together in loose, arm's length relationships (Yoo et al. 2012). The notion of collective innovation can also be found in the digital infrastructure literature, which generally assumes that digital infrastructures lack centralized control (Ciborra and Hanseth 2000); are developed by different actors in an incremental way (Star 1999); are bottomup (Constantinides and Barrett 2014) and are distributed across a diverse set of actors to support information exchange across organizational borders (Monteiro et al. 2014).

However, collective innovation processes are not without problems. Where the spheres of control of two loosely coupled actor groups intersect, actors struggle to gain control and to influence the processes and standards for collective innovation (Eaton et al. 2015). In complex ecosystems centered around digital innovation, actors have to resolve conflicting interests and business models (Nikayin et al. 2013), and there is a struggle for influence and control (Sanner et al. 2014; Henningsson and Henriksen 2011). As actors often have conflicting interests and business models the collective innovation processes can be blocked and come to a standstill (De Reuver et al. 2015; Markus et al. 2006). These standstills and blockages can lead to the dissolution of the collective innovation initiative before it has produced immediately tangible results (De Reuver et al. 2015). There is already a good understanding in the current literature of factors that lead to these blockages of collective innovation processes. Blockages can, for example, occur due to diverging interests (Klein and Schellhammer 2011); conflicts (Baland and Platteau 1996; Streeck 1990); a reduction or a lack of interdependencies (Walter et al. 2012; Monge et al. 1998); the availability of technology alternatives (De Reuver et al. 2015) or a lack of effective governance mechanisms (Ostrom 2000; De Reuver and Bouwman 2012). However, there is little understanding of how organizations can overcome standstills and progress with the collective innovation processes needed to bring digital innovations to market. This is the area which we set out to explore. The main question addressed in this paper is: How do collective digital innovation initiatives overcome standstills in order to progress in bringing the innovations to market?

In this paper we offer a novel perspective on how the process of developing collective digital innovations and bringing them to market can be understood, on the basis of a longitudinal interpretative case study of mobile banking in the Netherlands. We show how digital innovation emerges through a series of collective innovation processes that build upon each other through control point driven network reconfiguration and reframing, and we also show how control points are instrumental in understanding the efforts of collective action and the strategic moves that are taken as the process progresses towards market implementation. While we are aware of the high relevance of collective innovation involving customers in a co-creation process (Vargo et al. 2008), this is outside the scope of this paper: here we focus on collaboration between providers of services, platforms, infrastructures and other assets required for digital innovation.

The remainder of this paper is structured as follows. In the next section we discuss the theoretical framework and present the initial conceptual model for the study. Subsequently we discuss our interpretive case methodology. We then present the results of the case analysis and, discuss the findings. We end the paper with conclusions and recommendations.

\section{Theoretical framework}

To understand how to overcome standstills in collective digital innovation, we build upon insights from the theory of collective action, which explains how people or organizations collaborate towards a common goal (Olson 1965). Regarding social movements and technology innovation, collective action has been used to explain institutional innovation (Hargrave and van de Ven 2006) and challenges related to collective digital innovation (Markus et al. 2006; De Reuver et al. 2015; Rukanova et al. 2008; Rukanova et al. 2009; Van Stijn et al. 2009; Constantinides 2012; Constantinides and Barrett 2014). In literature, the concepts of (1) framing and (2) network configuration have been identified as important aspects in the understanding of collective innovation (Constantinides and Barrett 2014; Hargrave and van de Ven 2006; Van Stijn et al. 2009; Rukanova et al. 2008, 2009). We add the idea of control points to these concepts (ElalufCalderwood et al. 2011) to reflect the fact that, in collective digital innovation, control over resources is distributed across diverse actors in the network. We elaborate below on each of these aspects and their relevance to our study and present our 
initial conceptual framework, combining collective action and control point perspectives.

\section{Framing}

Framing is seen as an important concept in the understanding of collective innovation processes (Constantinides and Barrett 2014; Hargrave and van de Ven 2006; Van Stijn et al. 2009; Rukanova et al. 2008). We adopt the definition that Constantinides and Barrett (2014) use, based on (Goffman 1974) where "framing can be seen as a sense-making practice (Goffman 1974) that generates meaning for diverse collective movements" (Constantinides and Barrett 2014, p. 43). Within social movement theory, researchers also discuss framing contests in which the meaning of issues are created and manipulated (Campbell 2002).

Framing has received a lot of attention in the social science literature. Benford and Snow (2000) provide a review to capture the main themes in the framing literature. Here we provide some key concepts that are used in literature to analyze framing. Benford and Snow (2000) distinguish between diagnostic framing, prognostic framing and motivational framing as core framing tasks. They also discuss variable features such as problem identification and direction, flexibility and rigidity, exclusivity and inclusivity, variation in interpretative scope and influence (also with reference to master frames), and resonance. These are important aspects to consider when examining collective digital innovations as these innovations address problems or opportunities that may be perceived differently by actors over time.

With regard to the processes that lead to frame development, generation, and elaboration, a number of processes are identified: discursive processes; strategic processes and contested processes. Strategic processes are of specific interest to our study as they are deliberate and goal-oriented, and deployed for a specific purpose such as resource mobilization or attracting new members (Benford and Snow 2000). As parties do not control all resources themselves, we consider that strategic framing processes will need to be examined in relation to network mobilization efforts and the control points held by parties in the network. Attempts to link framing with network mobilization can be found in literature (Van Stijn et al. 2009; Rukanova et al. 2008, 2009) and later in this paper we elaborate on how we build upon these earlier attempts.

The last category of processes that Benford and Snow (2000) discuss concerns contested processes, which include counter-framing, frame disputes within a movement, and dialectics between frames and events. In the context of our study, frame disputes and counter-framing processes are particularly relevant to help trace how framing is shaped at different points in the evolution of the collective digital innovation, and how these changes help to unblock the collective innovation process. Kaplan (2008) analyzes the implications of uncertainty on framing contests, observing that "information ambiguity is the linchpin of strategy making in periods of uncertainty, and framing is key to explaining how actors cope with it... Strategic response is therefore constructed through the conflicts in frames and the purposeful action of managers seeking to make their own frames triumph over others." (Kaplan 2008, p. 748). The issue of uncertainty is important for the understanding of collective digital innovation, given the unknowns that are present when parties initially enter into a collective innovation. Therefore, an explicit acknowledgment of the ambiguity and the dynamics of framing over time is important for understanding the evolution of a collective digital innovation.

\section{Network mobilization}

Network mobilization is a key element in collective action literature (Hargrave and van de Ven 2006). As collective digital innovation necessarily involves multiple actors, it is essential to understand network mobilization and how the actors holding necessary resources are involved in the collective processes over time. When discussing network mobilization, Hargrave and van de Ven (2006) discuss mobilizing structures "which are the resources and organizations through which people engage in collective action" (p. 871). The concept of network mobilization has been further applied and operationalized in the context of digital innovation in the international trade domain (Rukanova et al. 2008, 2009). In their conceptualization, specific attention is paid to capturing and making explicit the complex processes of network mobilization by using a multi-level analysis. In this analysis, the innovators' efforts are placed at the center and the analysis gradually moves outwards to capture other relevant actors, nationally and internationally (Rukanova et al. 2008, 2009). In our study we will explicitly build upon this network conceptualization, to capture the network and to trace the evolution of the network over time. The link between network mobilization and framing has been further developed by van Stijn et al. (2009). Building on the multi-level network mobilization analysis earlier research (Rukanova et al. 2008, 2009; Van Stijn et al. 2009) illustrates that detailed analysis can be applied to trace the framing strategies that network actors utilize in their strategic framing processes. In our study we extend and build upon this earlier research.

\section{Control points}

To address the issue of distributed control, scholars have introduced the concept of control points. Control points are artefacts that enable the controller to exercise power over other actors in a socio-technical system (Elaluf-Calderwood et al. 2011). Control points are thus a source of interdependency in realizing a common good. The strength of a control point 
depends on four dimensions (Eaton et al. (2010, p. 462)): interchangeability (i.e. the extent to which control points can be replaced by other resources); demand (i.e. the extent to which a control point is required by other actors); value (i.e. the value of the control point to other actors); and time (i.e. the durability of the control point). In the context of changing value networks, Pagani (2013) points out that the competitive advantage of participation resides dynamically at control points that are seen as positions of value and/or power, and that the enterprises who hold these positions have a great deal of control over how the network operates and how benefits are distributed.

In attempting to better understand generativity in information infrastructures Tilson et al. (2010) look at the paradox of change and the paradox of control and derive a conceptual model of the socio-technical dynamics of digital infrastructures. Within their model, flexibility/stability can lead to generativity and this enables new patterns of socio-technical connections. These are influenced by the strategic actions of many actors. The new patterns of socio-technical connections that are enabled and the strategic action lead, respectively, to a blurring of social categories and new (contested) control points, which together engender new temporally stable sociotechnical configurations. The dynamics of this process reflects tussles between centralized and distributed control. Furthermore, the strategic actions of the many actors involved lead to the redevelopment of digital infrastructures, resulting in new forms of flexibility/stability. The interesting aspect of this model by Tilson et al. (2010) is that it takes a dynamic view and acknowledges that there are instances of tussles for control points which lead to new contested control points and to certain temporally stable socio-technical configurations. These insights are also very useful for examining collective digital innovation, as, at the commencement of a collective innovation initiative, parties will step out of their traditional environment where control points are predefined and enter into an arena of ambiguity, where the new distribution of control points requires definition. This process will initially lead to instability and a search for new control point configurations until a stable new order is reached. As Tilson et al. (2010) suggest, this stable new order may only last until something happens to disturb its stability, whereupon a new cycle begins.

Interesting insights that also take a dynamic view are provided by Dattée et al. (2018), who examine how firms maneuver within an ecosystem when uncertainty is high. They argue that in periods of high uncertainty it is unclear how control points will manifest themselves and actors will try to predict their potential, and try to understand what control points need to be established and defended at the present time in order to generate future value. They propose a process model that distinguishes between the phases of proto-vision (focusing on the state of enabling technologies and range of alternative futures); the envisaged blueprint (focusing on the clarity of envisaged interdependencies and clarity of envisaged control points) and enacted resonance (looking at internal and external momentum). These insights also reconfirm the dynamics that takes place in the network and the control points. However, Dattée et al. (2018) highlight issues such as the range of alternative futures, and how framing can help to make explicit how the actors perceive alternative futures and how these evolve over time.

\section{A framework for understanding the collective digital innovation process by tracing its evolution over time through the lens of framing and network configurations driven by control points}

Based on the literature review presented in the earlier sections, we view collective digital innovation processes as being characterized by a high level of ambiguity concerning how control is distributed in the new situation and by differing views on alternative futures (Kaplan 2008; Van de Ven 2005; Dattée et al. 2018). This ambiguity allows different actors to try to gain power over control points. As Dattée et al. (2018) point out, these control points are not clearly defined and actors have to predict what value the new situation will offer to them. There is considerable ambiguity and uncertainty surrounding these points, especially in the early stages of the innovation process. Furthermore, these processes can incorporate dynamics and stability, leading to contested control points and temporally stable socio-technical configurations (Tilson et al. 2010) which may be challenged in the future. In this process, strategic response is constructed through conflicts in frames and the purposeful action of managers seeking to make their own frames triumph over others (Kaplan 2008). Framing tasks can focus on the way the problem is defined and identified (diagnostic framing) or how the solution is envisaged (prognostic framing), or on the engagement of other actors (motivational framing) (Benford and Snow 2000), and strategic framing processes can be used to understand network mobilization (Van Stijn et al. 2009). Building on these insights, we arrived at our initial conceptual model (see Fig. 1).

In our model, we commence with the assumption that a trigger (represented in the top left corner of our model) leads to an initial collective digital innovation initiative at the period t1. As discussed earlier, initiatives often come to a standstill. We are particularly interested in understanding how these standstills are overcome, in order to allow the collective innovation to continue. To capture this in our model, we deliberately included an arrow pointing towards the concept of unblocking mechanisms that lead to collective innovation initiatives in the next period. Our case analysis will attempt to identify such unblocking mechanisms. The analysis of collective innovation in each period will focus on three aspects and their interrelationships, namely: a) What is the configuration 


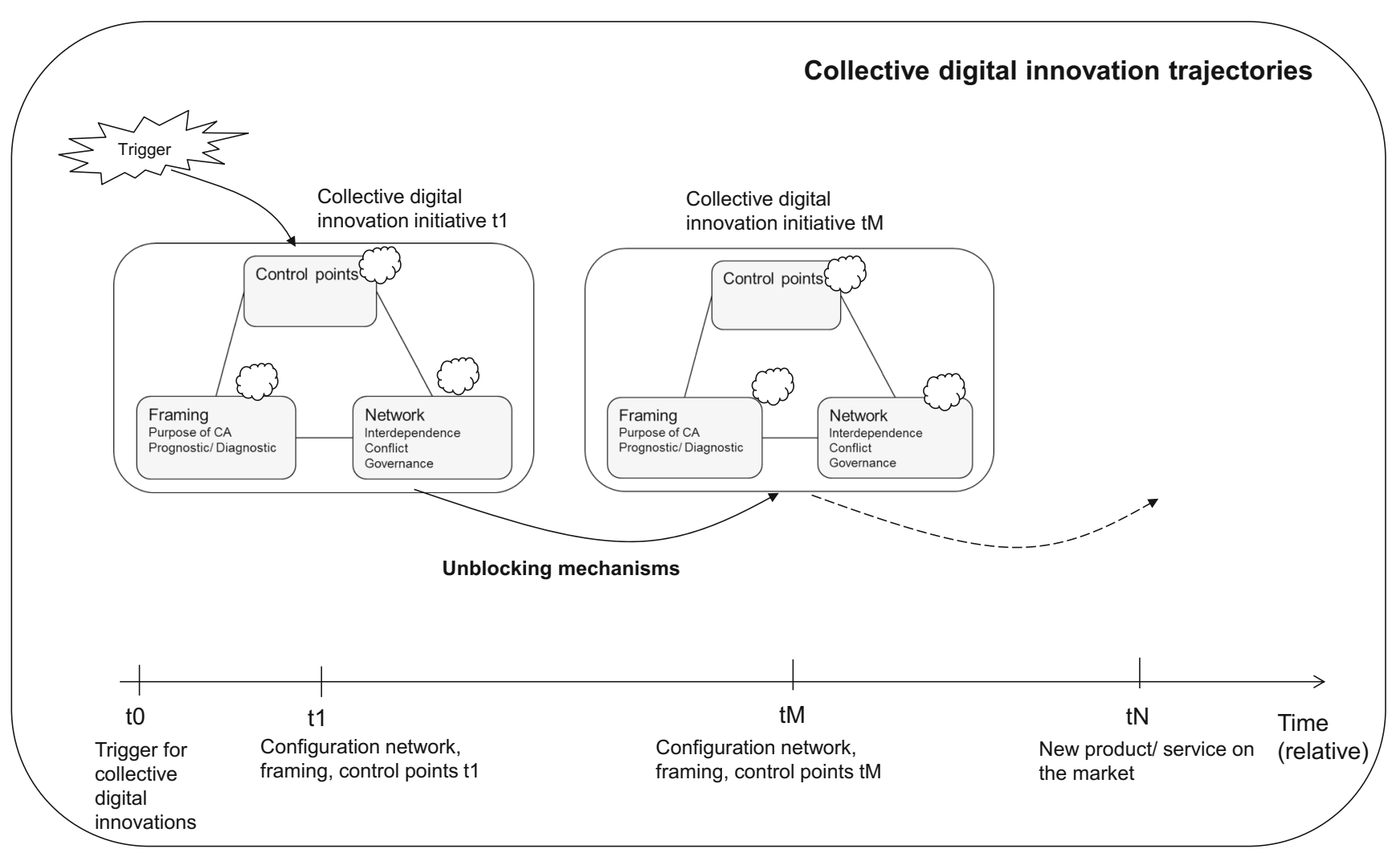

Fig. 1 Initial conceptual model for understanding the collective digital innovation process

of network partners participating in this initiative? We will look to identify interdependencies, conflicts and governance structures; b) How is this collective innovation initiative framed? Here we will look at how the goal of the collective innovation initiative is framed. We will pay attention to the diagnostic framing of how the problem is seen and to prognostic framing regarding potential solutions; c) We will look at the control points that are controlled by actors in the network. As discussed earlier, these innovation processes are highly ambiguous. We introduce a cloud symbol in our model to represent this ambiguity about control points: the network configuration or the framing can be a source of dynamics that can lead to changes in collective action initiatives over time. The goal is to examine this process until stable configurations are reached and the innovation is brought to market. We will use the initial model presented in Fig. 1 as a conceptual lens through which to analyze our case of the introduction of mobile payment in the Netherlands.

\section{Research approach}

In this section we motivate the choice of method, provide background information about case selection and explain how the data collection and analysis were performed. Furthermore, as we argue that control points are domain-specific, in this section we explain the logic that was followed to identify domain-specific control points for the mobile payment domain, and we continue to use this in the analysis section.

\section{Methodological foundations}

In our research we follow the interpretative and contextualist case study approach (Orlikowski and Baroudi 1991; Klein and Myers 1999; Walsham 1993) which is a well-established approach in the area of information systems. Interpretive studies are "aimed at producing an understanding of the context of the information system, and the process whereby the information system influences and is influenced by the context" (Walsham 1993, p. 4-5). We also follow Pettigrew's contextualist approach to change (Pettigrew 1985, 1987, 1990; Pettigrew et al. 2001) as Pettigrew argues that a study of change has to place change in its historical, processual, and contextual setting and to examine developments over time. Such an approach is suitable for our study as it will allow us to look at the broader context and to elaborate on the processes by which collective digital innovations evolve over time. In line with the interpretative tradition, our study is not intended to be a positivist test of our conceptual framework, nor do we use the conceptual framework as a predictive model. The goal is to analyze and explain the phenomena under consideration. In terms of the theory types in information systems research that Gregor (2006) distinguishes (i.e. theory types for analysis; 
explanation; prediction; explanation and prediction; design and action) our study can be seen predominantly as theory for analysis and explanation. The study is based on an indepth single longitudinal case study, however, as argued by Walsham $(1995,2006)$ this does not inhibit the achievement of generalizable results.

\section{Case selection}

In order to understand how a collective innovation attempts to overcome blockages to brings the collective innovation to market we took the mobile payment domain for the case study. There are several reasons why this domain is of interest. First of all, the mobile payment domain is a complex domain which requires collective innovation processes to be deployed by diverse actors including banks and telecom operators (Dahlberg et al. 2008). Secondly, mobile payment requires a shift in controls: some control points that were traditionally maintained by banks are now taken over by other players (Ozcan and Santos 2015). Thirdly, digital mobile payment innovations often struggle to achieve collective action, with only a few examples of successful commercialization (De Reuver et al. 2015). Fourthly, we have access to historic data of innovation efforts in the Netherlands (starting with the socalled TRAVIK initiative). This enabled us to trace the developments over time and to look at how the network evolved and became transformed, overcoming blockages and bringing mobile payment solutions to market after the dissolution of the TRAVIK initiative.

As a starting point for our case study we took the TRAVIK project, a collective action initiative (in the form of a joint venture) by the three largest Dutch banks and the main Dutch telecom operators to develop mobile payment solutions for the Dutch market. Taken in isolation, this initiative can be seen as a collective action failure (see De Reuver et al. 2015). However, once the joint venture was dissolved, the collective action efforts of the participating organizations evolved and became transformed, and most of the participating parties were able to bring mobile payment solutions to market. These collective and incremental innovation trajectories will be the focus of our analysis.

\section{Data collection and analysis}

As discussed earlier, we conducted our study in an interpretative, processual tradition (Markus and Robey 1988; Pettigrew 1990; Walsham 1993) with a focus on the actions, decisions and events whereby the TRAVIK project unfolded over time from its inception in 2009 to the formal closure in 2012, and the follow-up initiatives until 2016, when a number of parties initially involved in TRAVIK succeeded in bring mobile payment solutions to market.
The data collection and analysis of our historical case study followed a hermeneutic process (Klein and Myers 1999), iterating between the emergent theoretical understanding and the data on which it was based. The majority of the data collection was performed on the TRAVIK project, as reported in an earlier contribution (De Reuver et al. 2015). This in-depth engagement with the TRAVIK project allowed us to gain a deep understanding of the domain and the concerns and considerations surrounding the development of mobile payment for the Dutch market. Table 1 in Annex 1 provides a summary of the data collection efforts spanning the period 2009-2012. In 2016, the authors of this paper revisited the TRAVIK case and collected additional data to identify developments after the dissolution of the TRAVIK initiative and whether actors who were initially involved in TRAVIK had been successful in bringing mobile payment solutions to market. The data collection for the period 2012-2016 was based on follow-up contacts with members involved in the TRAVIK initiative, as well as desk research of available online materials such as press-releases, news, videos, annual reports announcing the introduction of mobile payment solutions involving actors previously participating in TRAVIK, and related initiatives. A selection of key online sources used to capture the developments after 2012 is provided in Annex 1, Table 2.

We took a processual approach to the data analysis starting from TRAVIK and tracing a continuum of follow-up initiatives. We identified and followed a number of initiatives that evolved after TRAVIK: a) the Leiden Initiative involving the banks and one of the mobile operators; $b$ ) the introduction of a mobile payment solution by one of the banks after the conclusion of the Leiden initiative; c) the VISA initiative. For each of the initiatives we examined (1) what was the network configuration, (2) what was the framing, (3) what were the control points and who held them. We subsequently looked at strategies that parties used to overcome blockages in collective innovation to move on to a next configuration of collective action. We followed the initiatives until they resulted in the introduction of mobile payment solutions. In the case analysis section, we apply our conceptual framework (Fig. 1) to each of the initiatives.

For the analysis of the network, we used a simplified version of the network visualization and conceptualization approach of Rukanova et al. (2009), including the key actors participating in the network. We were able to capture snapshots of the network and trace its evolution and transformation through the different initiatives. We conducted a high-level analysis looking at the framing of the different initiatives and how framing evolved over time. Regarding control points: the literature does not provide detailed guidance on how to identify control points and domain-specific control points. However, the identification of domain-specific control points was an important step in our case analysis, as we needed to 
understand the control points held by the banks and which control points they were prepared to surrender in order to enter the mobile payment market. Therefore, we dedicate a separate section in our method chapter to a detailed discussion of how we dealt with the identification of domain-specific control points in the mobile payment case. It is important to make this logic explicit, as we will show that different network configurations emerge surrounding a specific control point (i.e. secure identification and validation), which could be covered by different parties, each offering different technical solutions (e.g. via SIM, the phone or the cloud).

\section{Domain-specific control points for the mobile payment domain}

Control points are an important part of our conceptual framework but it was not immediately clear how they could be identified when we started the analysis process. In our view, control points are domain-specific and differ per subject domain. A key challenge was how to specify these domain-specific control points, taking mobile payment as our focus of analysis. We looked for a stable starting point that could help us to study the evolution of domain-specific control points and to identify new control points.

We looked at traditional transactions in the traditional physical world and attempted to identify the key control points that people held in the physical world (we will call these basic control points). We subsequently studied how these basic control points became refined and transformed within a digital intermediated world where digital innovation plays a role. In this way, we aimed to identify control points that appeared in the intermediated digital world while at the same time systematically keeping the link to the physical world as a reference point for the basic control points.

We used a business transaction as an economic exchange as the starting point for the identification of basic control points. In a traditional transaction, the customer (the buyer) receives goods or services in return for a form of compensation (something else of value in return). Goods or services are exchanged for money, if money is used as a medium of exchange. In a traditional transaction the buyer has money, promises to pay and completes the actual payment. The seller is aware that the buyer possesses money, can request the buyer to pay for the goods or services and receives the payment. In this direct exchange in the physical world the buyer is in control of his money, promises to pay and is in control of the actual payment (handing the money over to the seller).

In an intermediated world, banks took control of payments. In this case, the money for the payment is not held directly by the customer, but by the bank on his behalf. Banks also play a role in facilitating the payment (the communication between the buyer and seller, as well as their banks and the actual settlement). As banks took over control points related to payment and the intermediation process there arose a need to introduce new control points. Banks have control over (1) holding funds on behalf of the customer; (2) facilitating payments (communication aspect) once they receive instructions to do so and (3) clearing and settlement, performing the actual money transfer from the buyer's account to the seller's account. There is a legal basis whereby the banks can hold these specific control points (such as holding funds and clearance and settlement), based on licenses which prohibit unlicensed actors to cover these control points.

In an intermediated world where payment is done via the bank there is no direct contact between the buyer and seller. Therefore, it is essential to identify both parties. Additionally, as the bank holds the money on behalf of the buyer, it is essential to identify and validate the identity of the buyer and link the buyer to his funds. There are two other control points needed in an intermediated digital world to link the customer to his account, a process called issuing, and a process of secure identification and validation when transactions take place. This leads us to the two additional control points (4) issuing (i.e. creating a bank account and creating a card or a digitized card that is linked to the account), and (5) secure identification and validation (See Fig. 2 below).

It is also vital to have some form of (6) technology on the customer's and the merchant's side to facilitate identification and validation. Examples of such technology are chip cards for the customer and chip readers for the merchant. As technology evolves, new alternative technologies (e.g. near-field communication cards) are developed to cover this control point.

The control points related to the customer's issuing bank and the merchant's acquiring bank can mostly be mirrored. What is missing is the link that enables money to be transferred from the issuing bank to the acquiring bank (in the physical world, the process of the customer handing over money to the merchant). This defines the control points of the network providers. These can be national providers, or international such as Mastercard and VISA. They hold two important control points, i.e. (a) they define the rules and technical standards for performing transactions between the issuing and acquiring banks and (b) they provide the network. Figure 2 above captures the logic of how we derived the control points. The right-hand side of the figure lists the basic control points that we identified for intermediated digital payment transactions.

As we see in Fig. 2, many more control points need to be introduced in an intermediated digital world to ensure that the basic control points that apply to a physical world transaction also hold true in an intermediated digital world. By following this logic, we identified an initial control point configuration. These control points have led to some temporally stable 


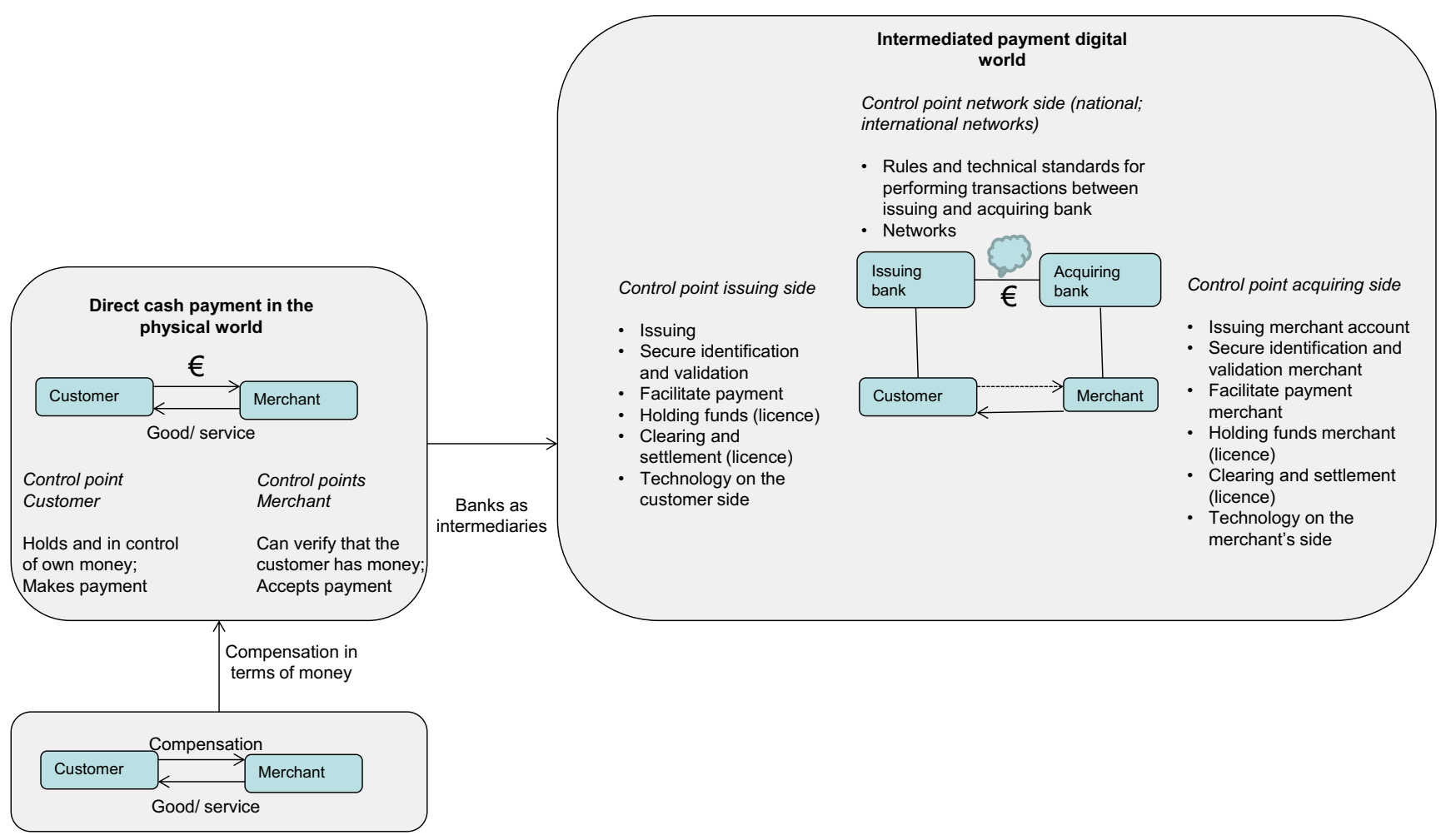

Fig. 2 Deriving the basic control points for the payment domain

configurations where banks have traditionally covered the majority of control points. ${ }^{1}$ We will use this situation as a starting point to examine the digital world that challenges some of the control points in such a temporally stable configuration.

Building on this initial identification of control points in the banking domain, our case examines the dynamics of banks who wish to enter the mobile payment market and have to surrender the secure identification and validation control point as a result.

Before we proceed with the case analysis we need to make one observation. Our study was empirically driven. It was interesting to observe that customers were not involved in the collective action initiatives that we analyzed. The customers appeared to be end-users who benefit from mobile payment services rather than active participants in the collective action. However, in other cases of collective digital innovations (e.g. digital innovations that allow customers to determine whether the products they buy are fair trade products) the

\footnotetext{
${ }^{1}$ In the traditional situation, most of the control points are held by the bank and banks can sub-contract certain processes such as the issuing of cards or the operation of card readers to other parties. However, the banks remain in control of these specific control points. Furthermore, for reasons of simplicity we do not look into the relationships between the banks and the network service providers for inter-bank payment. For the case analysis we assume a stable situation where all the control points in the initial situation are held by banks, and we examine the situation where the banks are willing to surrender some control points so that they can benefit and enter the mobile payment market.
}

customer will often appear to be a powerful player in the collective action initiative.

\section{Results}

In this section we present our case findings. In the method section we discussed how we performed the analyses using our initial conceptual framework (Fig. 1). In this section we present the case background, we analyze TRAVIK and the follow-up initiatives, and subsequently we trace the evolution of these initiatives (see Fig. 7), the unblocking mechanisms and related strategies that were used to further the initiatives and how these efforts ultimately allowed parties to bringing the innovations to market.

\section{Case background}

In 2009, three telecom operators in the Netherlands, KPN, TMobile, and Vodafone and three of the major banks, i.e. Rabobank, ABN AMRO and ING formed a collaborative initiative named TRAVIK, of which they were all shareholders. The aim of TRAVIK was to establish a shared digital infrastructure for authenticating mobile payment users and for handling transactions. This can be seen as a collective action initiative where the banks and the telecom operators joined forces in the attempt to bring mobile payment to market. Telecom operators fulfilled an important role as they 
controlled SIM cards, which were, at the time, the only technological option for securely authenticating users when making a mobile payment. The TRAVIK project was dissolved in 2012, without achieving the common goals. There are many reasons why the initiative did not succeed (see De Reuver et al. 2015). One reason is the emergence of technological alternatives such as cloud computing and card emulation, which enabled handset manufacturers to take over the position of telecom operators. After 2012, the TRAVIK network dissolved into two major spin-offs. One of these was pursued by Vodafone. Vodafone, an international company, joined forces with VISA to pursue its mobile payment ambitions internationally, in the so-called 'VISA initiative'. The second spin-off was undertaken by the three banks, who conducted a local pilot with telecom operator KPN, the so-called 'Leiden initiative'. The Leiden initiative was led by the three banks with $\mathrm{KPN}$ as a sub-contracting partner. The goal was to learn about mobile payment collectively, even though each bank would commercialize the technology separately. After the Leiden initiative was completed, the banks set up their own networks of partners to pursue mobile payments. Handset manufacturers (such as Apple and Samsung) and providers of operating systems (OS) such as Android emerged as new partners in these latest network configurations.

\section{Case analysis}

We will analyze each of the initiatives below, using the initial conceptual framework (Fig. 1) and examining the network, the control points and the framing. For the mapping of the network we adopt the network visualization of Rukanova et al. (2009) and for the analysis of the control points we use the control points derived in the methods section (Fig. 2).

\section{TRAVIK t1a and t1b}

As discussed earlier, the key parties in the TRAVIK initiative are the three major Dutch banks and the three major Dutch telecom operators. Figure $3 \mathrm{a}$ and $\mathrm{b}$ represent the control points distribution and network configuration at the beginning and at the end of the TRAVIK project. The figures capture two moments showing the banks and telecom providers as key actors in the network (lower part of Fig. 3a and b).

The Vodafone group is also depicted in the networks of Fig. $3 \mathrm{a}$ and $\mathrm{b}$ to illustrate that while TRAVIK is a national initiative, one of the actors belongs to a company with international operations. The top sections of Fig. 3a and b show the control points. In both cases the control point secure identification and validation is marked, because, in TRAVIK, banks are willing to surrender this control point in order to enter the mobile payment market. At the start of TRAVIK (Fig. 3a) telecom providers were the only players able to take over this control point. As depicted in Fig. 3b, at the end of TRAVIK new international actors such as handset manufacturers (Apple, Samsung) and operating system providers such as Android had started to emerge. As a result, after TRAVIK there are three categories of actors that can take over the control point of secure identification and validation and allow banks to enter the mobile payment market.

At $t 1$ we can see a strong interdependence between the banks and the telecom companies, as the banks cannot cover secure identification and authentication in the mobile domain, whereas the telecom companies can. There is a resource heterogeneity which allows for these groups to cover the basic control points for bringing a collective innovation on the market. As the parties depend on each other and as there are no alternative technologies (at $\mathrm{t} 1 \mathrm{a}$ ) for the secure element, the interdependence between banks and telecoms is strong. With new opportunities for other parties to cover the control point the banks were less dependent on the telecom operators at the end of TRAVIK (tlb).

As a result, at $\mathrm{t} 1 \mathrm{~b}$ the power of telecom providers in the network and the interdependence with the banks became weaker.

Regarding network governance: at t $1 \mathrm{a}$ the collective action was started as a joint venture. At $\mathrm{t} 1 \mathrm{~b}$, the joint venture initiative was discontinued.

Framing is the third element from our conceptual framework. The framing of the scope of the TRAVIK initiative was as a national initiative. The framing of the solution at tla (prognostic framing of the collective action objective) was to set up a common platform. At t $1 \mathrm{~b}$ this ambition had evaporated as there were other prognostic frames (having the secure element in the cloud or in the phone instead of the SIM card) starting to appear, offering new opportunities, and the TRAVIK collective action initiative was discontinued.

\section{Leiden initiative t2a}

After TRAVIK was discontinued the so-called Leiden initiative was started. It included the three major banks that had taken part in TRAVIK. Only one of the telecom operators from TRAVIK (KPN) joined this initiative (see Fig. 4). The interdependence between the banks and the telecom operator KPN was still weak, due to alternatives offered by handset manufacturers and operating system providers. The network governance shifted from a joint venture (TRAVIK), where telecom operators and banks operated as equal partners, to a situation where the banks took the lead and KPN became a sub-contracting partner. The framing of the collective action objectives also changed: from the development of a joint platform to joint learning, where the banks agreed to collaborate but that after the pilot each bank would decide how to proceed.

The framing of the initiative remained focused at the national level.

The discontinuity of the Leiden initiative was agreed upfront, as the parties wanted to jointly learn about the potential of mobile payment, including the new context of alternative 


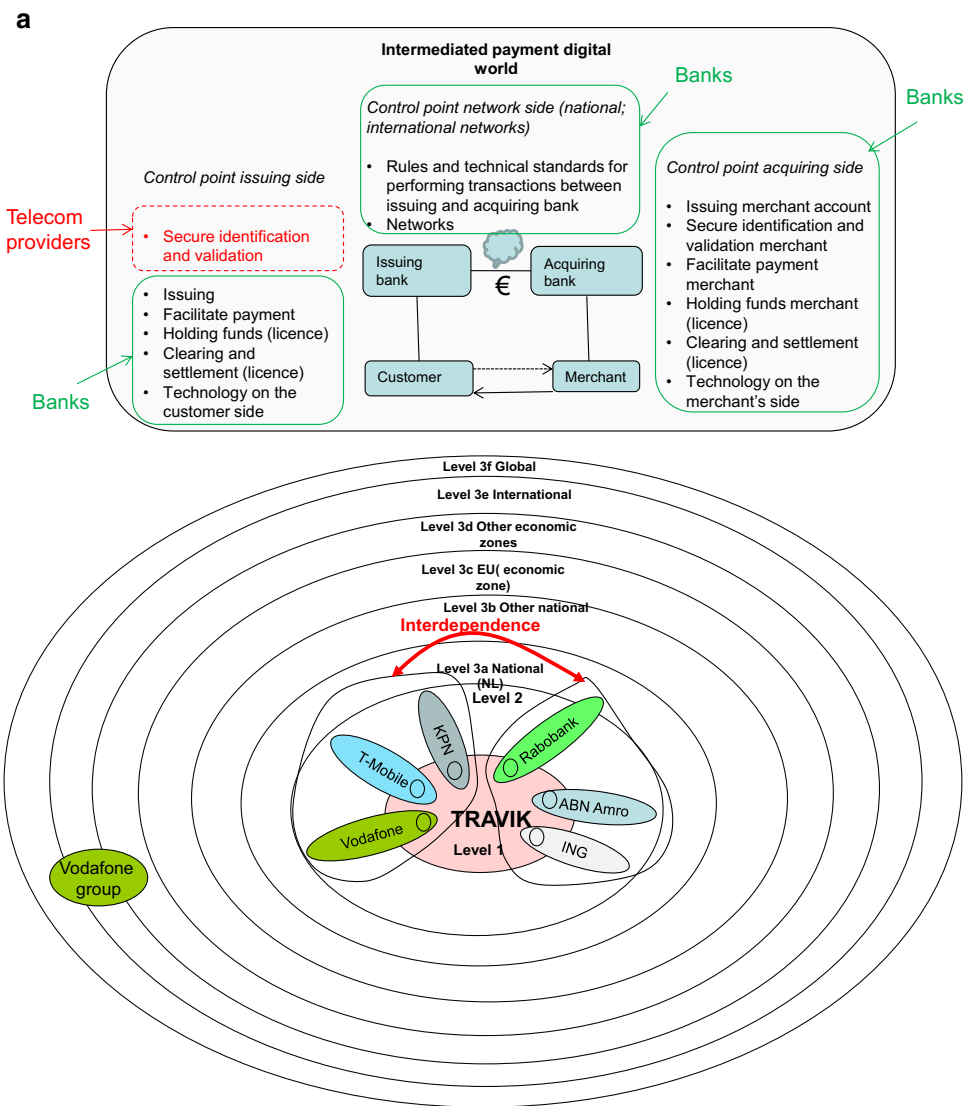

Fig. 3 a TRAVIK at time tla. b TRAVIK at time t1b

technologies to cover the secure element control point, with the banks then proceeding separately.

We looked at the transition from TRAVIK to the Leiden collective action initiative and reflected on how the obstacles were overcome. We observed two unblocking mechanisms, namely the reframing of objectives (from joint platform to joint learning); and a reconfiguration of the network. In the new network configuration the interest heterogeneity was reduced by lowering the number of network participants covering the same control point (the i.e. related to the secure element). In TRAVIK there were three mobile network operators while in the Leiden initiative there was only one, reducing the number of parties with the same interests acting within the same initiatives and reducing the possibility of a conflict of parties with competing concerns. Additionally, the reframing of the governance structure from joint venture to subcontracting allowed for a clearer leadership structure. In this way, all key control points remained covered, so that, in principle, the parties could still proceed with the development of a collective innovation. In this network configuration there was interest heterogeneity, as there were still three banks in the Leiden initiative network covering the same control points, which could potentially lead to problems. It is therefore not surprising that the parties agreed in advance to collaborate for joint learning but to continue separately after the project.

\section{Rabobank partnering with Samsung and subsequently KPN} (t3)

After the Leiden initiative, the banks proceeded with separate collective action initiatives building on the knowledge that they had accumulated during TRAVIK and the Leiden initiative. For the sake of simplicity we only follow one of the banks (the Rabobank) but the other two banks exhibit a similar pattern.

The choice of going separate ways to market mobile solutions led to new network configurations (see Fig. 5). In this network configuration there was only one bank covering the respective control points (reducing the interest heterogeneity that was present in the Leiden initiative with the participation of three potentially competitive banks). Rabobank initially partnered with Samsung in the new network configuration (marked with 1 in Fig. 5) to cover the secure element control point.

The secure element control point was initially covered by the handset manufacturer, using the mobile phone to handle the secure element. Interestingly, Rabobank subsequently moved away from this idea and chose to place the secure element on the SIM, announcing a partnership with KPN, the telecom operator that had collaborated in TRAVIK and the Leiden initiative. One explanation of this move can be 

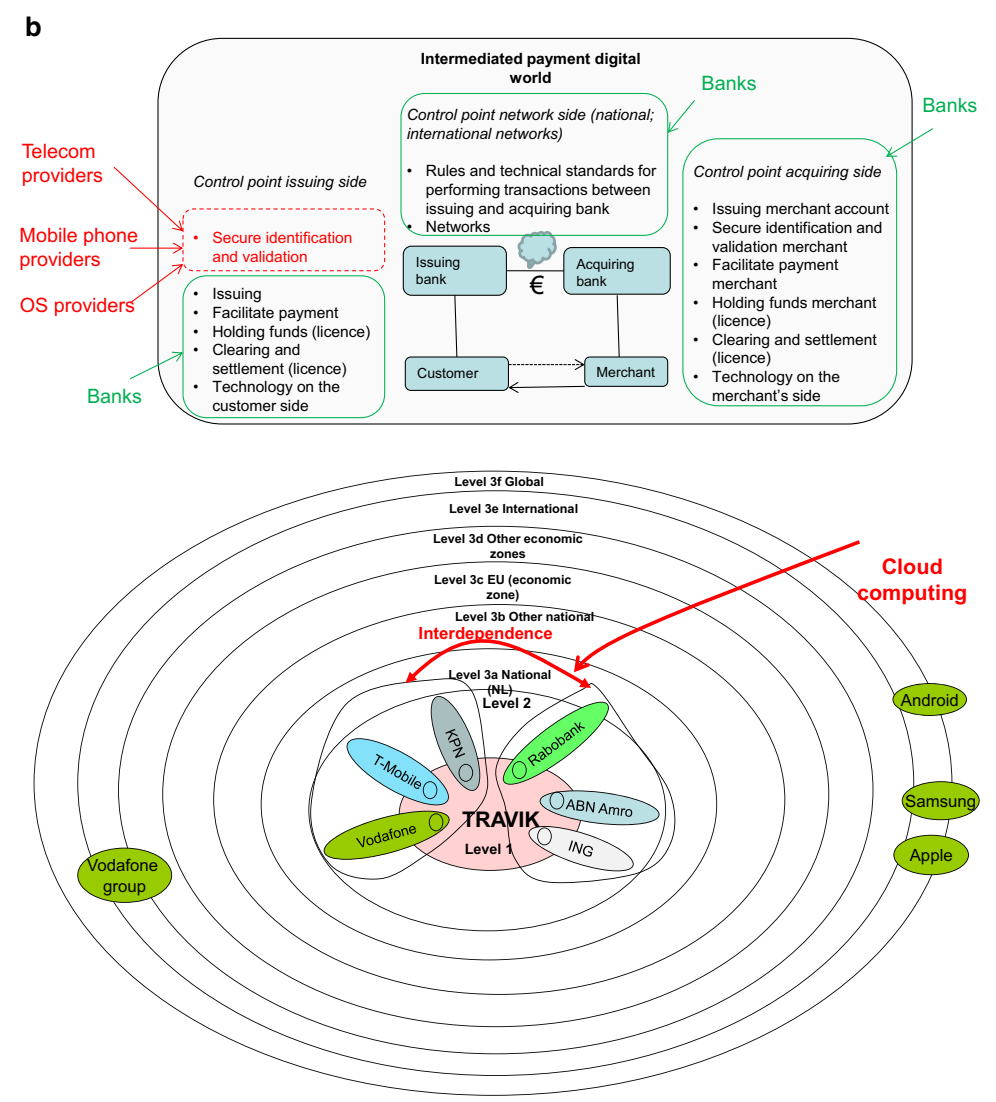

Fig. 3 continued.

related to the link to the customer. Rabobank is predominantly a national bank. Samsung is a global player with a customer base in the Netherlands, but KPN has a major market share in the Netherlands thus bringing new market opportunities to Rabobank.

Reflecting on the discontinued Leiden initiative, there are a number of mechanisms and related strategies that we observe that led to the overcoming of obstacles and the emergence of the follow-up initiative. These are: (1) reframing of objectives - from joint learning (Leiden initiative) to joint product development (the individual bank's initiatives). (2) reconfiguration of the network first of all by substitution (substituting one actor covering the security element control point by another actor covering the control point by alternative means), as well as exclusion - reducing the number of actors covering the same control point (by excluding the other banks that had been part of the Leiden initiative). These strategies allowed the banks to move ahead to market specific products after the Leiden initiative.

\section{The Vodafone way and the VISA initiative (t2b)}

Looking at TRAVIK and the Leiden initiative we see that only one of the three telecom providers became part of the
Leiden collective action initiative. T-Mobile and Vodafone did not take part. We have limited information on the subsequent mobile payment ambitions of T-Mobile but we were able to trace the follow-up activities of Vodafone, which continued to pursue options in the area of mobile payment.

Vodafone was able to cover the basic control points related to the secure element but in order to bring mobile payment to market it needed to find ways to cover the other basic control points that had been covered by the banks in the TRAVIK initiative. Unlike KPN, which is predominantly a Dutch company, Vodafone NL is part of Vodafone group, an international company with international ambitions in the area of mobile payment. After TRAVIK, Vodafone joined a collective action initiative alongside VISA. Vodafone reframed its ambitions from a national to an international level. In terms of network it replaced the Dutch banks (able to cover the key control points on a national level) with VISA, and in this way was able to cover the key control points at an international level.

These moves by Vodafone are captured in Fig. 6, where Vodafone covered the secure identification control point and was able to operate internationally, and VISA was able to cover other bank control points internationally. 

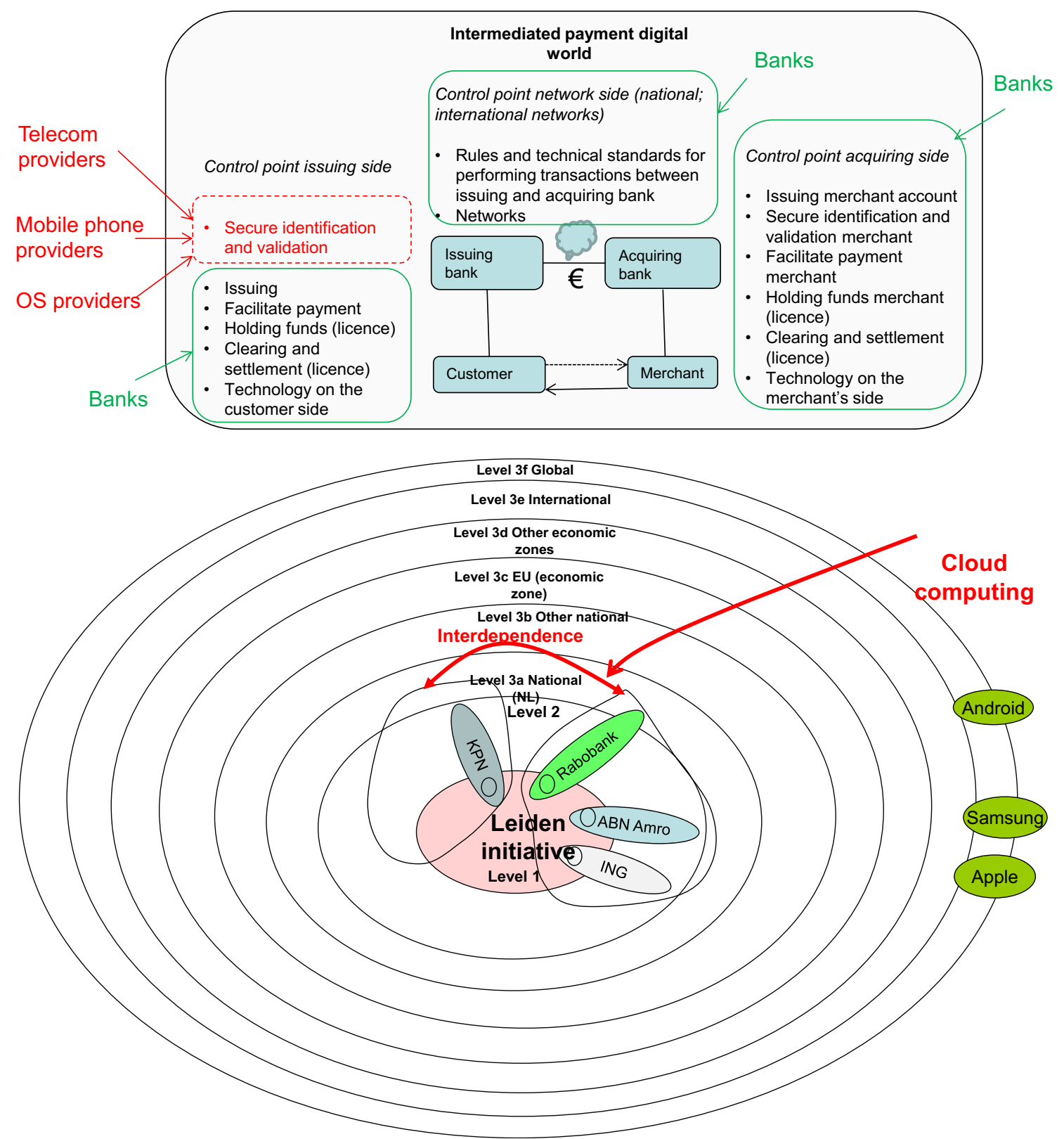

Fig. 4 The Leiden initiative

\section{Summary of how the initiatives built upon each other to bring digital mobile payment innovations to market}

Figure 7 shows how the collective action initiatives evolved by tracing both the evolution of the network over time, and the unblocking mechanisms and strategies that we identified.

\section{Discussion}

Our analysis reveals the TRAVIK collective action as one stepping stone in the collective innovation processes that ultimately resulted in the mobile payment solutions available on the market today. By applying our initial conceptual framework (Fig. 1) to the case and based on the case findings, we developed our Framework of control point driven collective action process for digital innovation (See Fig. 8).

If we look at the TRAVIK case in isolation we can see it as a failure. Earlier research explains in detail why the initiative was terminated (De Reuver et al. 2015). In retrospect, we can ask the question: Why did the parties invest so much time and effort on collaboration without succeeding in bring together the mobile payment to market? Why were they not far-sighted enough to see 

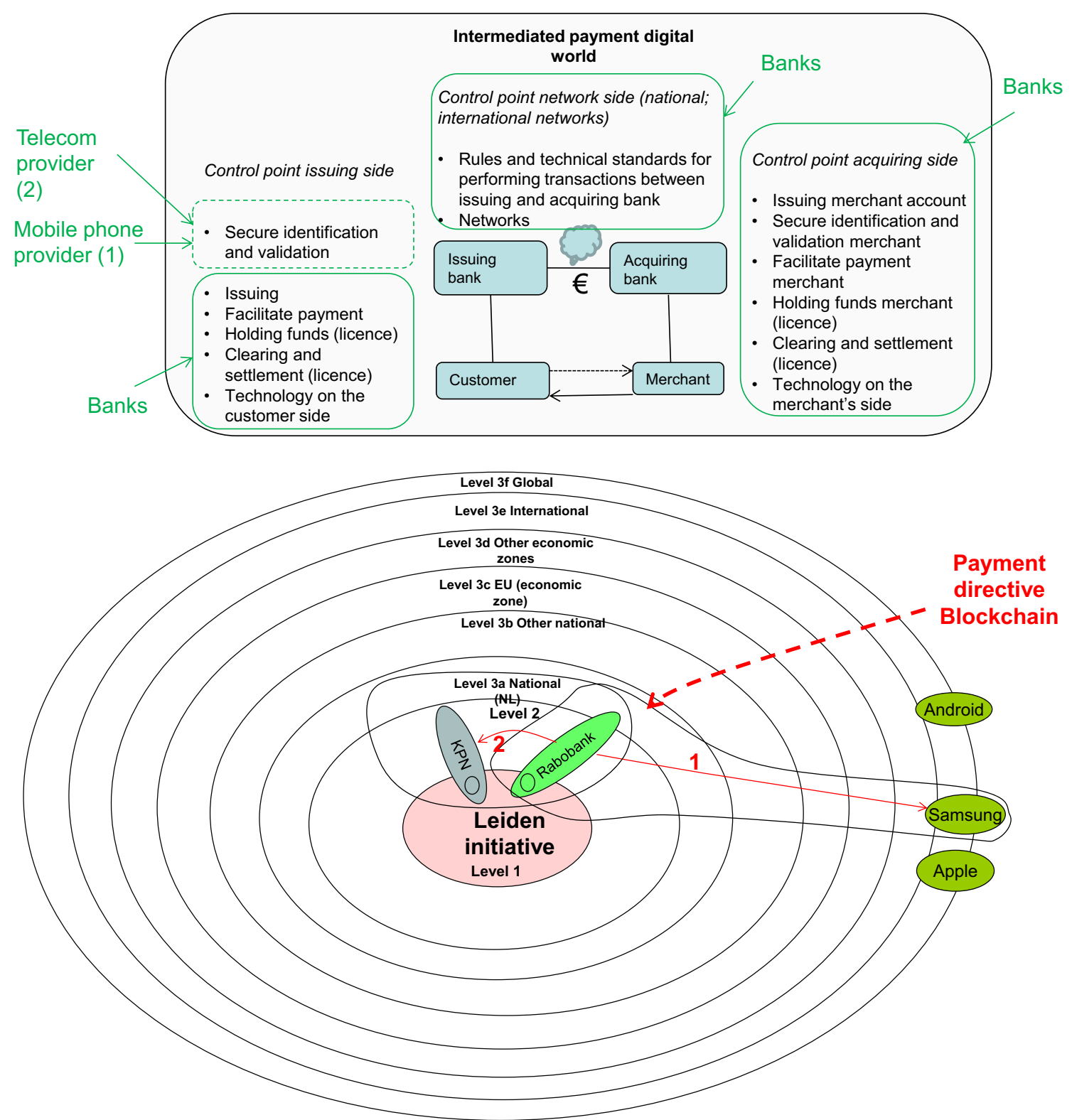

Fig. 5 Rabobank partnering first with Samsung (1) and subsequently with KPN (2)

potential conflicts and to realize that the initiative was unworkable? They could have investigated other, winning configurations from the start. One of the reasons is that collective innovations take place in an environment that is extremely dynamic and characterized by high levels of uncertainty and ambiguity, and where, for example, changes in technology and regulations can change interdependencies. In other circumstances, if, for example, cloud computing had not appeared as an alternative, the interdependencies among the parties in the TRAVIK network might have remained strong: perhaps the willingness of parties to collaborate would have been greater and they would have sought means to overcome the conflicts. We cannot know.
What we do know, however, is that the TRAVIK initiative was terminated but, over time, collective innovation processes proceeded. Most of the parties that were involved in the TRAVIK initiative are now active in the mobile payment market. By looking at collective innovation as a process, the TRAVIK initiative is a collective action initiative that was succeeded by a number of other collective innovation efforts. It was one of a number of steps in this process, where, starting with a high level of uncertainty and ambiguity, parties gained knowledge about the new innovation domain (mobile payment), gained knowledge about the network and through learning they ultimately found win-win configurations to market mobile payment innovations. 

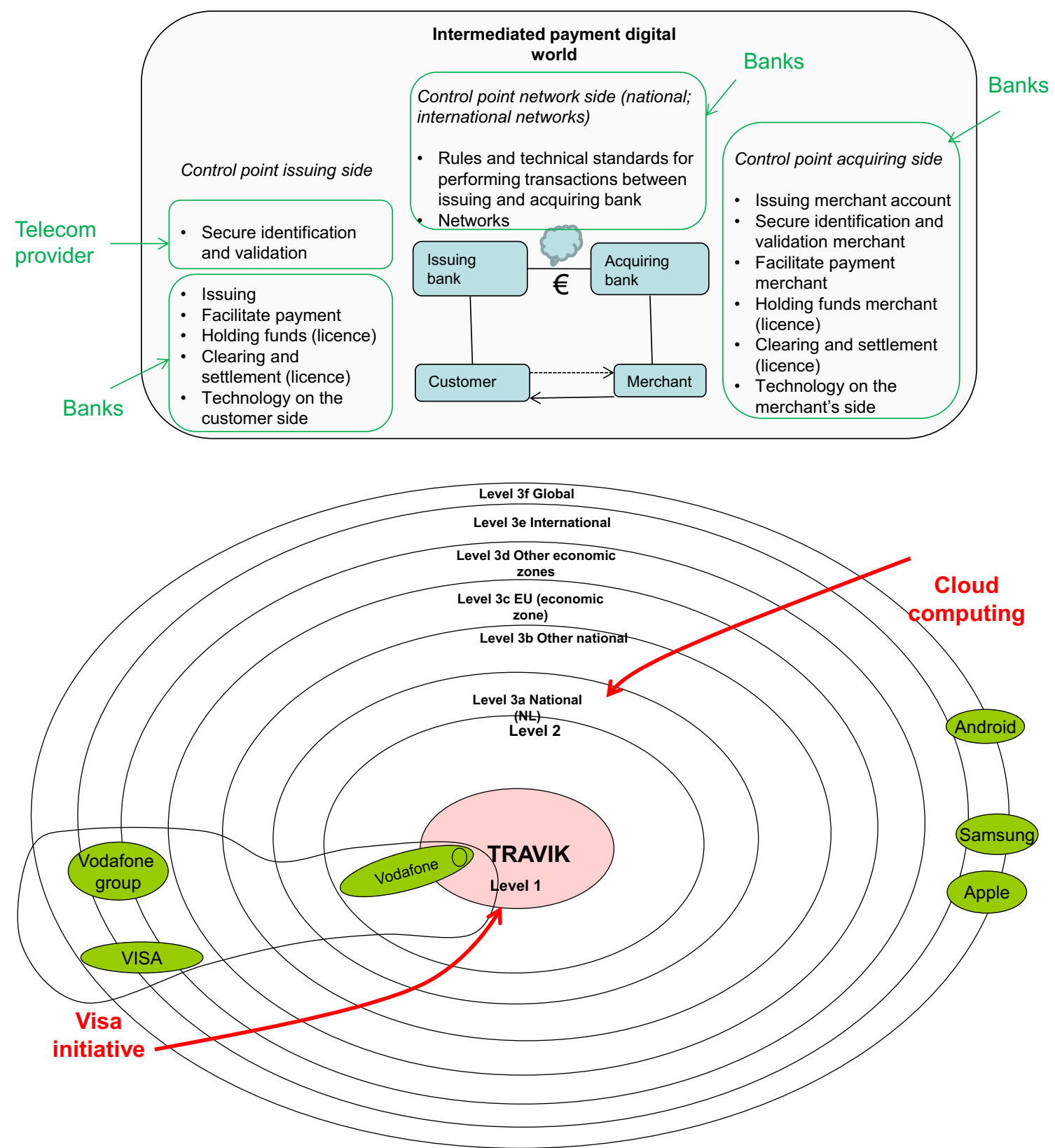

Fig. 6 Vodafone and the VISA initiative

It has been discussed in collective action literature that, as collective action initiatives develop, they can link or branch out and interact with other collective action initiatives or social movements, and become part of larger collective action efforts (Blumer 1969; Kling and Iacono 1998). Here we can see that other collective action initiatives branched out from TRAVIK and parties looked for other configurations and initiatives both nationally (Leiden initiative) and internationally (VISA initiative) once the initial network configuration was dissolved. It is these series of collective action efforts that brought the mobile payment solutions of the parties involved to market. We argue that in order to understand collective innovation it is essential to look at collective innovation initiatives such as TRAVIK as a part of a process and in a wider perspective of succession with follow-up collective actions and involvement. In this wider perspective they are no longer a failure, but are key in revealing how digital innovations are shaped and build upon each other to bring ideas to implementation. 


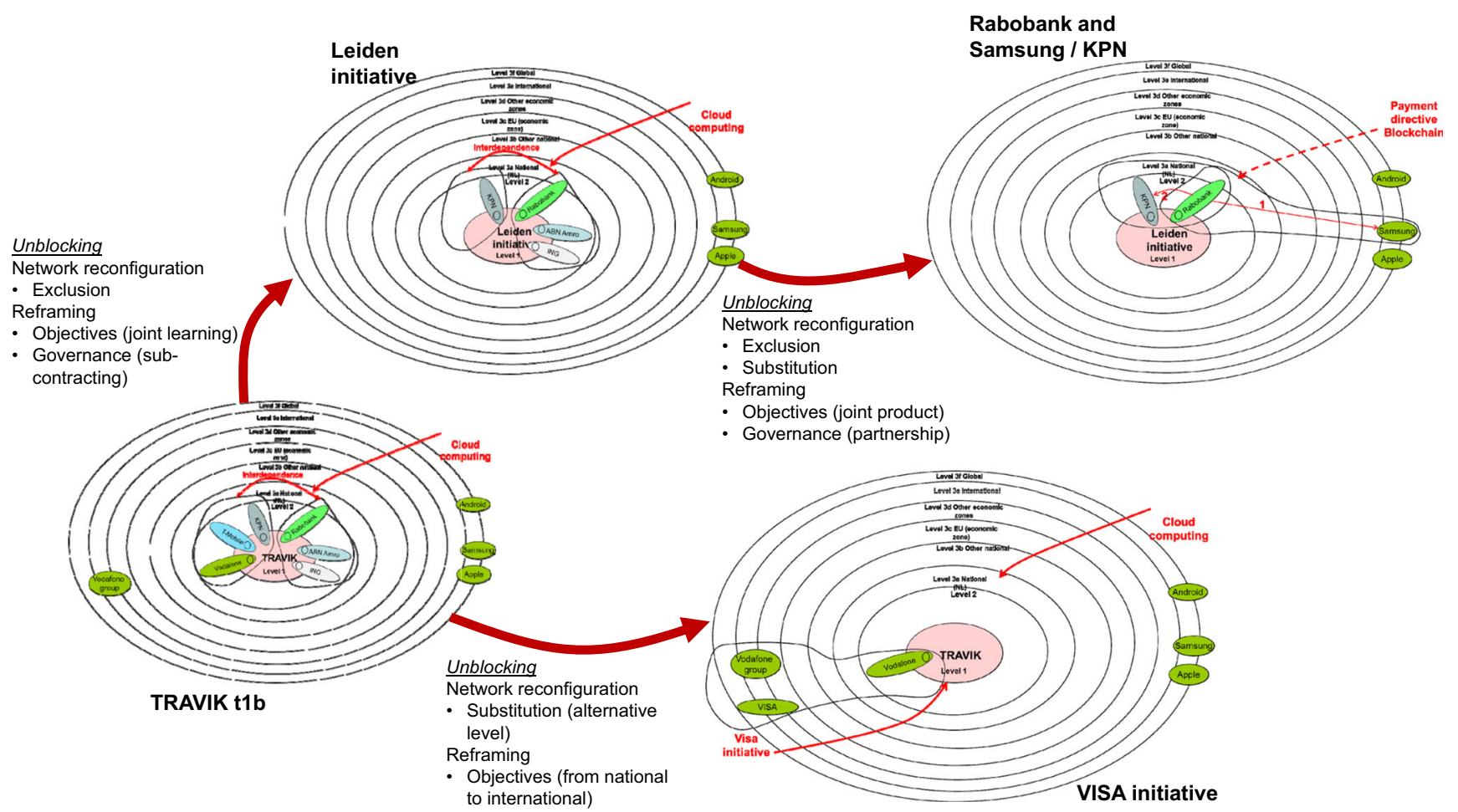

Fig. 7 Evolution of the network of collective action initiatives over time and the unblocking mechanisms and strategies involved. This figure aims to illustrate the evolution of the network of different collective action initiatives. Due to space limitations the full network details may not be visible (the full details of each of the networks for each of the initiatives is

\section{Control points}

In our case, we can state that in the course of history control point configurations have changed, with innovations that allowed physical transactions to be intermediated by banks. As a result, banks gained control points and acquired a temporally stable configuration of key control points related to payment. The emergence of mobile technology triggered a change in these temporally stable configurations. Banks had to obtain the capabilities they lacked to operate in the mobile world and to enter the mobile payment market. At this point, the control point configuration was challenged and entered an unstable state, where there was a need for new actors. As the case illustrates, this triggered a search process where a number of initiatives built upon each other until configurations evolved that allowed parties to arrive at new, temporally stable control point configurations. This search process was driven by network reconfiguration and reframing, where parties accumulated knowledge about the network and about the framing of the solutions, and were able to identify new temporally stable network configurations. In the resulting temporal configurations banks were no longer in control of all the control points and presented in a larger format in Fig. 3a to Fig. 6.) However, Fig. 7 allows visualization of major structural changes in the network such as exclusion of actors or inclusion of other actors, as well as the unblocking mechanisms and strategies deployed

different control point configurations emerged. For example, Rabobank entered into a temporal network configuration with a mobile phone company (Samsung) and subsequently changed strategy to partner with a mobile operator (KPN) to arrive at a new temporally stable configuration of control points. But these network configurations, though temporally stable, can be challenged, for example if new technologies force banks to surrender more control points or if other changes occur. We will return to this issue but before that we discuss the two unblocking mechanisms that were identified in the case (network reconfiguration and reframing) as well as the related strategies which allowed the initiatives to move beyond gridlock and to reach a new situation of temporally stable configurations where all control points are satisfied.

\section{Network reconfiguration and reframing driven by control points}

In the case we identified two unblocking mechanisms, namely network reconfiguration and reframing. The strategies related to these unblocking mechanisms are further explained in the sections below. 


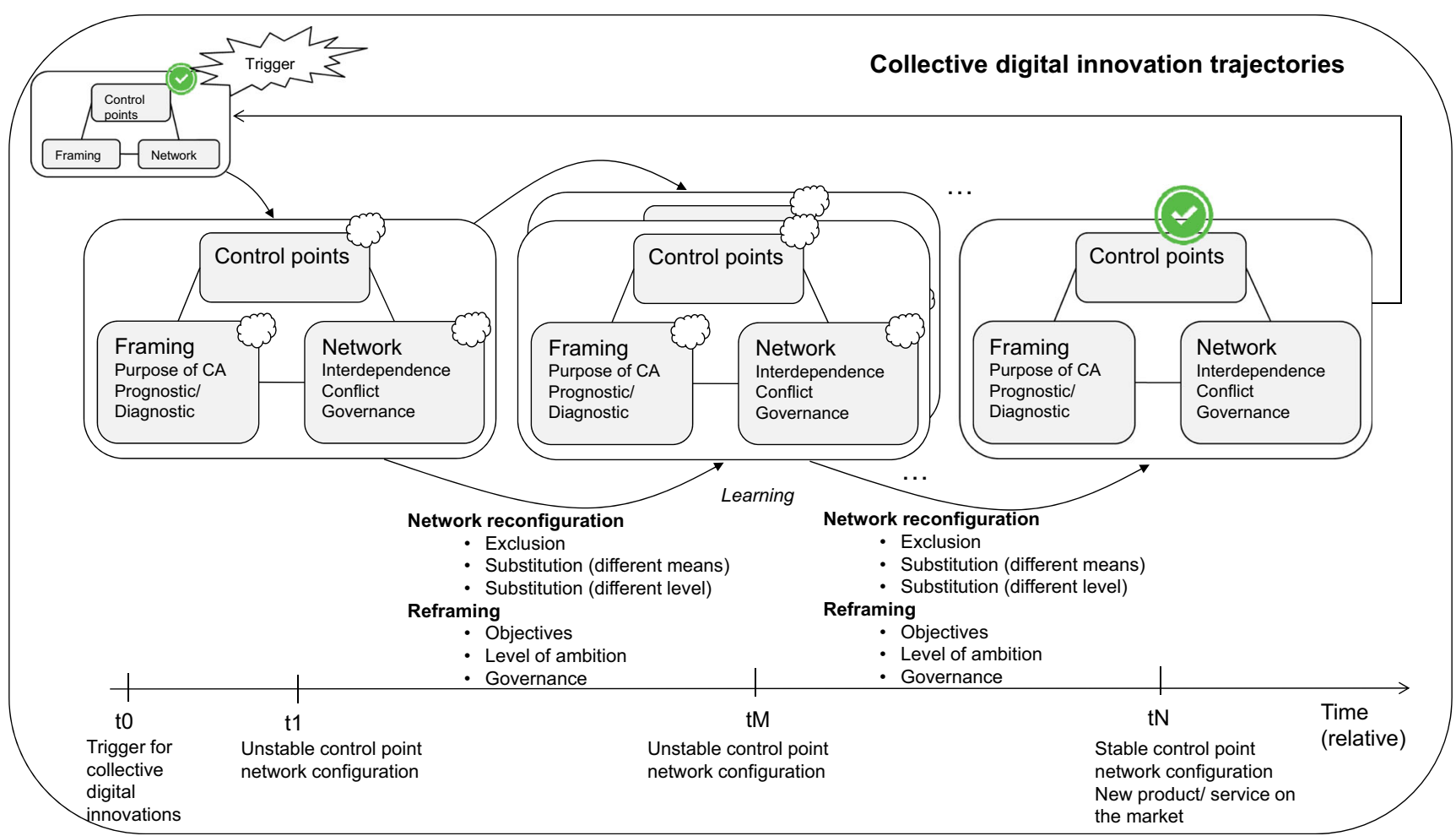

Fig. 8 Framework of control point driven collective action process for digital innovation

\section{Network reconfiguration}

Regarding the network reconfiguration unblocking mechanism, we found the following strategies that helped to overcome standstills, namely (a) reconfiguration through the exclusion of participants holding the same control point; (b) reconfiguration through substitution by actors offering alternative means to cover a control point; (c) reconfiguration through substitution by actors covering a control point at a different level (geographical coverage). Each of these is discussed below:

Reconfiguration through the exclusion of participants holding the same control point In the Leiden initiative, the banks took the lead and reduced the number of telecom operators from three to one. This reduced the complexity of the network with less participants covering the identification and validation control point. There was still an issue of network complexity between the banks, as they all covered the same control points. In the third step, the reconfiguration applied to the banks. In the final collective action network configurations which concerned commercialization of a product there was only one bank involved. Thus, competing banks benefited from joint learning in the collective action efforts of the Leiden initiative but they engaged in follow-up collective action efforts that excluded rivals who held the same control points when commercializing the actual product.
Reconfiguration through substitution by actors offering alternative means to cover a control point Substitution by actors covering the same control point with other means is another strategy for reconfiguring the network that was used in the process of bringing mobile payment solutions to market. In the individual initiatives of the banks following the Leiden initiative, the telecom operators that held the identification and authentication control point through a SIM-based solution were substituted by actors who could cover the same control point by other means (in the case of Samsung, via the phone).

Reconfiguration through substitution by actors covering a control point at a different level (geographical coverage) A third network reconfiguration strategy that we identified that enabled the overcoming of blockages was by substituting actors holding a control point and operating at one level (national) with actors operating at another level (international). This can be seen in the case of Vodafone joining the VISA initiative. When TRAVIK stopped, Vodafone was not able to launch mobile payment solutions on its own, as it did not hold the control points that were initially held by the Dutch banks. In alignment with its international operation, Vodafone joined collective action efforts where the control points that were initially covered by the Dutch banks (national level) were now covered by a global actor (VISA). 


\section{Reframing}

Reframing is the second unblocking mechanism that we identified, in several forms. We saw a number of strategies related to reframing, namely: (a) reframing of objectives; (b) reframing of the level of the collective action ambition; (c) reframing of governance. Related to reframing of objectives we saw a shift of objectives from offering a joint platform (TRAVIK), to joint learning (Leiden initiative), to offering a joint product (payment solutions offered by the individual banks). Regarding the reframing of the level of ambition, Vodafone decided to fill in the control points originally covered by the banks operating in the Netherlands with a player who operated internationally, reframing the collective action ambitions from the national to the international level. Furthermore, we found (c) reframing with respect to governance strategy. When compared to TRAVIK, we identified that subsequent collective action initiatives changed the governance model and we observed joint ventures, sub-contracting and partnership.

\section{A framework for the emergence of collective digital innovation through the process of network reconfiguration and reframing driven by control points}

Figure 8 builds upon our initial conceptual framework (Fig. 1) and enriches it with findings from the case. The resulting framework is what we call the Framework of control point driven collective action process for digital innovation. The framework indicates that in such trajectories, bringing digital innovations to market is a search process, where different digital innovation initiatives will build upon each other and where unblocking mechanisms (in this case, network reconfiguration and reframing) help parties to learn and to reduce ambiguity until they are able to make decisions and enter into a stable situation where a network configuration of partners covering all the control points in the new situation has been found. In this process, multiples of such temporally stable network configurations can evolve, which can in the future be challenged by new triggers. In Fig. 8 we explicitly list the unblocking mechanisms i.e. network reconfiguration and reframing that we identified in the case, as well as the respective unblocking strategies related to these mechanisms (i.e. for the network: (a) exclusion; (b) substitution (different means) and (c) substitution (different levels). For reframing: (a) reframing of objectives; (b) reframing of the level of ambition and (c) reframing of governance). These mechanisms and related strategies are not intended to be exhaustive and future research may identify and expand on this list.
In the above model we have indicated that there can be ambiguity concerning control points. This ambiguity can, for example, concern alternatives to cover a specific existing control point. The control point analysis that we performed for arriving at the basic control points allows us to zoom in and view the control point aspect in more detail. This detailed analysis of control points (i.e. opening the black box of control points presented in Fig. 9, as will be done in the next section) can be beneficial for conducting a more detailed domain-specific control point analysis and to study disruptive triggers of collective digital innovation trajectories.

\section{Reflection on prospective further use of domain-specific control points for strategic analysis of potential disruption/opportunity triggers}

In this section, we reflect on whether and how our framework may inform future understanding of distributed control and collective innovation processes in the banking industry and beyond. Earlier we explained how we derived the domain-specific control points in our study by going back to the basics of a transaction as an exchange of goods/services for some form of compensation. We then moved on to identify the payment part of the transaction that has since been intermediated by banks and we have further identified control points that are held by the banks. In our case, we zoomed in on a collective innovation process that only concerns a single control point, namely the secure identification and validation control point that was held by the banks. Banks were ready to surrender this control point in order to enter the mobile payment market and we traced the dynamics, the different technical solutions and the respective actors with control over these technical solutions and how this process evolved to bring mobile payment solutions to market. Conversely, we saw that actors such as telecom companies, phone companies and OS developers were able to build capabilities related to the control point of secure identification and validation in their own domains, and that this capability allowed them to enter a domain that was previously dominated by the banks. At the same time, banks were able to make a switch to mobile technology and offer mobile payment services to their customers.

However, there are still many control points in the payment domain that are held by banks. Making these control points explicit can be useful for identifying other actors who may enter this domain. For example, the new Payment Services Directive of EU (PSD2) creates the possibility that the control point "facilitate payment" that is now held by banks could be opened up to other actors such as payment service providers. Similar 


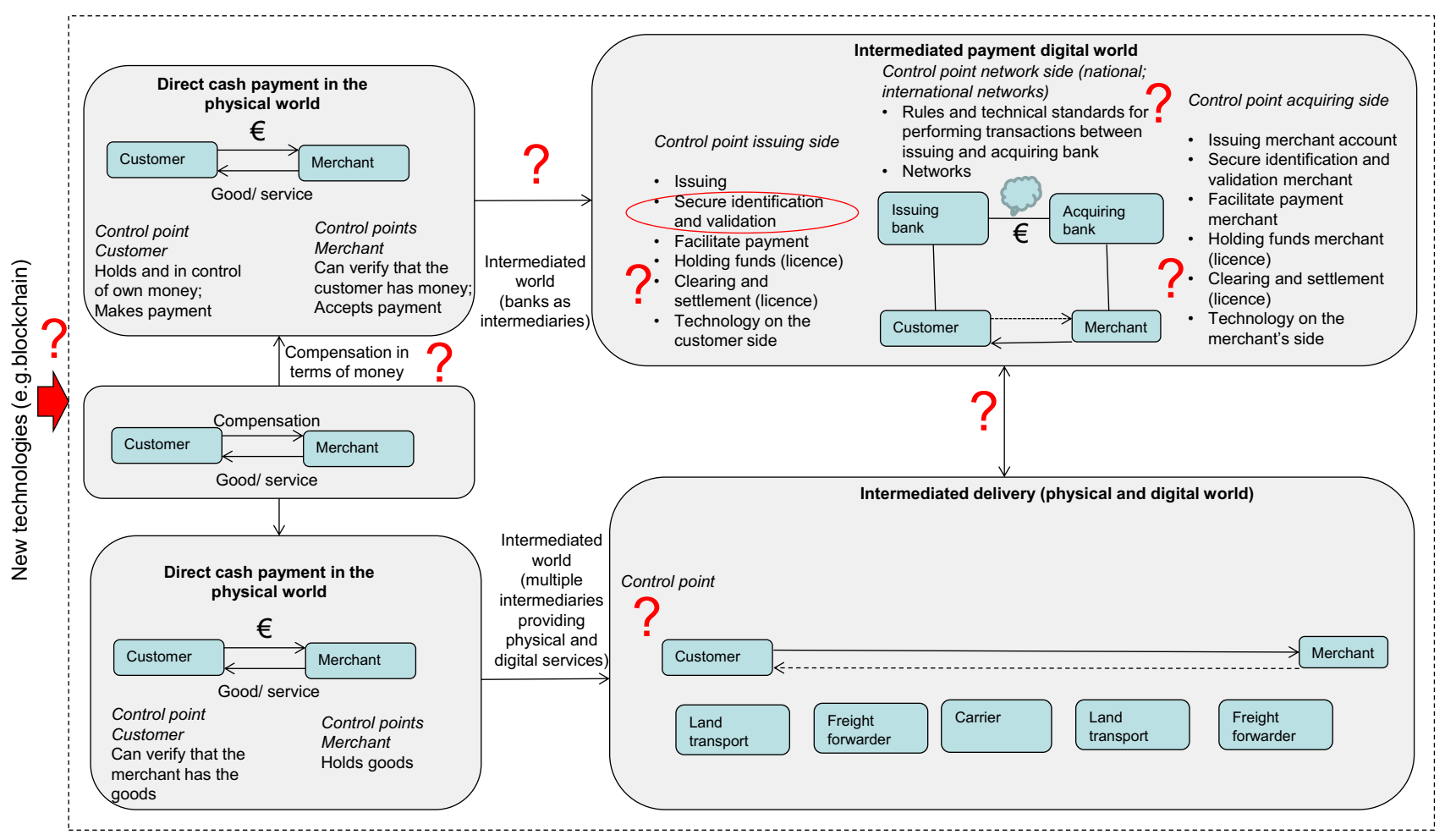

Fig. 9 Using control points to identify future triggers of threats/opportunities to the initiation of collective digital innovation

analysis can be done by looking at other control points, and banks and other actors can consider their own strategic approach. In this context, other control points could be introduced if certain activities are further intermediated or if new developments require that they are removed. Tracing the line of reasoning, one can surmise that some of the key assumptions of how banks operate as intermediaries would change as a result of using blockchain, cryptocurrency or other new developments. This is shown in Figure 9 with the question marks that move back from the detailed control points identified in the right-hand side of the figure towards the left-hand side which returns to the starting point of transactions that take place in the physical world. Following this path one can question the assumptions on which a bank's existence is based, as an intermediary to facilitate payment based on traditional currencies. By questioning these assumptions, completely new intermediated worlds have appeared in recent years where cryptocurrency is used as medium of exchange.

The control points that we derive based on the business transaction (Fig. 2) can also be expanded to capture control points that are related to the transfer of goods from the seller to the buyer (the lower right section of Fig. 9). Following a similar logic to the explanation for the payment part of the transaction, but now focusing on the goods transfer part of the transaction, we can say that in the traditional world the buyer and the seller were in direct interaction and the seller would hand over the goods. Now, the process of bringing the goods from the seller to the buyer (especially in a cross-border businessto-business setting) is highly intermediated with freight forwarders, customs brokers, carriers, terminals and trucking companies responsible for handling the goods or information about the goods along various parts of the chain. The information exchange regarding these processes and the related digital innovations are an important component of this process (Rukanova et al., 2018). A further analysis of key control points can reveal opportunities for network configurations to evolve, where actors from other domains can move in and cover control points traditionally held by actors who are involved in the goods transfer part of the transaction. This analysis of how companies take over control points or move from one domain to another may provide an interesting area for further research.

\section{Reflection on potential applicability of the framework in understanding mobile payment developments in countries other than the Netherlands}

Having discussed these possible directions of the use of control points, it is worth looking at cases of mobile payment that have been implemented in other countries and reflect on whether our findings and the framework 
derived from a Dutch case could be useful in understanding developments in other contexts. We do not intend to be exhaustive and we have only limited access to other cases via internet sources and other secondary sources such as published materials, but we will take a few examples to reflect on and illustrate the logic of how our findings can also be applied to these other situations. We will do that by reflecting on the introduction of mobile payment in Kenya and in Denmark and Sweden, as valuable comparisons to the Dutch case. Let us take the Kenyan case ${ }^{2}$ first. In many countries, when moving from a direct exchange towards an intermediated exchange, banks have taken most of the control points related to money transfer (such as issuing, secure identification and validation etc.). The banking system in Kenya was not well developed and accessing banking services in remote rural areas was a great challenge. With the introduction of mobile phones, mobile network operators recognized an opportunity and were able to cover most of the control points traditionally held by banks. The system used in Kenya is MPESA and was launched by Safaricom, one of the largest mobile network operators in the country. Users have an M-PESA account and can credit money through one of Safaricom's agents to their M-PESA account. Users can withdraw money by visiting another agent who checks that there is sufficient money in the account, or the user can perform mobile payments via mobile phone. In the Kenyan situation we see an example of mobile network operators taking a majority of control points usually fulfilled by banks in the areas of issuing, identification and authorization. However, the mobile network operators do not cover the control point of holding funds, and this control point, essential to arrive at a complete solution, is covered by the agents who are linked with the banks. The Kenyan case is more extreme than our Dutch case, where banks held most of the control points and mobile operators only attempted to take over one of the control points, related to secure identification and authentication. In the Kenyan case, we see the opposite situation, namely that most of the control points are taken over by the mobile network operator and only a few of the control points are left to the banks (via agents). Even though the two cases are entirely different, the control point model as presented in Fig. 9 appears to be equally applicable for understanding the Kenyan case from a control perspective.

\footnotetext{
${ }^{2}$ Information on the Kenyan case was collected via internet sources, and publications (Kimenyi, M.S., Ndung'u, N. S., 2009, available at: https:// www.brookings.edu/articles/expanding-the-financial-services-frontierlessons-from-mobile-phone-banking-in-kenya)
}

The introduction of mobile payment in Denmark and Sweden is equally interesting. In both cases, collective innovations were initiated by the banks and the banks entered into collaboration. In the Danish case, once the collective innovation had been started and the discussions on how to launch mobile payment solutions were underway, one of the banks pulled out of the collective initiative and launched its own solution. One possible explanation of why the bank ceased collaboration is that the collective initiative was moving too slowly and there was a fear that external players such as Apple (via Apple Pay) would enter into and take over the Danish mobile payment market. This bank also had to solve the issues of identification and authentication. The bank made use of the Danish national identification and authentication system to cover the corresponding control point. This is a different route to that taken in the Dutch situation, where, rather than choosing between keeping the secure element on the SIM, on the mobile phone or in the cloud, they used other solutions: the national ID number (CPR-number) or a more secure solution called $\mathrm{NemID}^{3}$ that was already in place and used for government services and banking. Such national identification solutions are also available in other countries. This shows yet another alternative solution to cover the secure identification control point. As the bank launched its solution on the Danish market earlier than the other banks, it managed to acquire a large market share in Denmark, leaving other banks little space to compete in once they had developed their own solution. These developments can also be captured by our model (see Fig. 8): what we see here is a much shorter path to market compared to the Dutch case, as the winning bank pulled out of the collaborative initiative and soon afterwards reconfigured the network by exclusion (leaving the others out) and reached a stable control point configuration by making use of national ID systems and solutions. In the Swedish case, a similar solution to cover the control point for secure identification was also developed, relying on the national ID system and a form of electronic identification issued by several banks in Sweden. Unlike the Danish case, the Swedish banks collaborated, and several banks in Sweden now offer mobile payment solutions. What is interesting about the Swedish case is that the Bankgirot clearing system, originally developed for instant payments, was used for the actual transfer. This could be seen as an alternative actor covering the control point on the network side (see Fig. 2), where the Bankgirot clearance system can be seen as taking over

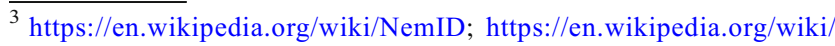
MobilePay
} 
the control point from traditional banking systems and offering cheaper alternatives related to the control point on the network side of the actual transfer.

Coming back to the Danish case, we can also make an observation about the attempts to upscale the solution internationally. Unlike the Vodafone and VISA initiative which was successfully scaled up, the Danish bank had limited international success with its mobile payment solution, succeeding in entering the Finish market but failing in Norway. This is not surprising, as in the VISA Vodafone initiative both parties held the respective control points on an international level, meaning that VISA and Vodafone had established international customer bases, each holding the respective control points at the international level. One possible explanation for the limited international success of the Danish bank is due to it having a limited customer base and presence in several Scandinavian countries but without a wide international coverage of control points as compared to VISA and Vodafone.

We only performed a quick appraisal of these cases and further research will be needed to examine them in detail. On a high level, however, it seems that the models (i.e. our framework, Fig. 8, and our control point models Fig. 2 and Fig. 9) that we derived from the Dutch case can be useful to analyze and compare mobile payment developments in other countries.

\section{Conclusions}

In this paper we show how collective digital innovations emerge and are brought to market through a series of collective digital innovation processes that build upon each through a process of network reconfiguration and reframing driven by control points. The framework that we have developed helps us to understand the processes and actions that the parties utilized to bring digital innovations to the market and can potentially be used to identify other possible courses of action and potential new network configurations. This paper can be seen as a contribution to the emerging body of research in the digital innovation literature which uses collective action. Our theoretical contribution is that we combine the collective action perspective with the control point perspective. This allows us to better understand the dynamic moves that key stakeholders make and how they overcome blockages to their attempts to bring collective digital innovations to market.

Regarding the practical implications of our findings: collective action efforts for digital innovation will continue to be undertaken. Initial attempts to bring digital innovation to market may not immediately succeed: changes in the environmental conditions or internal dynamics of the initial collective action configuration can bring the initiative to a standstill. Based on insights gained from the mobile payment domain, we recommend that parties keep a focus on control points. When standstills occur, parties can look for alternatives by, for example, reconfiguring the network (through exclusion, substitution via alternative means, or substitution by focusing on a different level); or by reframing (of objectives, levels of ambition or of governance). This may enable parties to overcome standstills and to search for new collective action configurations to cover, or even circumvent, control points. When such new network configurations are not immediately evident, one available strategy is to wait until a new technological development disturbs the established configurations, thus revealing new opportunities. One such example of an emergent technological development is the electronic SIM. While the SIM card has always been a major control point for telecom operators, the emergence of eSIM will weaken their position and will provide opportunities for new actors to enter the field. Keeping a focus on control points can be instrumental for organizations to identify potential new network configurations and potential threats to current configurations. Collective digital innovations can be witnessed in numerous domains and often span long periods of time. Learning how to manage standstills can make these processes more efficient and effective, allowing for faster implementation and upscaling.

A limitation of our study is that it is based on one domain, i.e. mobile payment, and predominantly reflects experiences in the Netherlands. Further research can proceed in a number of directions, namely: First, the framework developed in this study can be applied to a number of other domains where digital innovations are taking place, including energy (e.g. smart grid initiatives), healthcare (e.g. electronic patient record initiatives), and international trade (e.g. digital trade infrastructure initiatives for supply chain visibility). Such studies will help to enrich and refine the framework, allowing for a much richer understanding of innovation processes. Second, further research can focus on eliciting the basic control points in different domains. This would allow the derivation of guidelines and more structured recommendations on how to identify the basic control points in new domains. Third, research can focus on whether and how the framework can be used proactively. For example, we now see the emergence of blockchain as a new technology which is likely to disrupt existing practices in the financial and other domains. It is valuable to speculate on how current network configurations will be disturbed by this new technology and to identify scenarios and control point configurations that open opportunities for new players to enter the playing field or existing players to redefine their positions.

Acknowledgments This research was partially funded by the CORE Project (nr. 603993), which is funded by the FP7 Framework Program of the European Commission. Ideas and opinions expressed by the authors do not necessarily represent those of all partners. 


\section{Annex. Data collection: Overview of key sources}

Table 1 List of Interviewees for the data collection TRAVIK (2009-2012)

\begin{tabular}{lll}
\hline Data collection TRAVIK & \\
\hline Code & Organization & Position of the interviewee \\
\hline B1 & Bank 1 & Manager Consumer Banking \\
B2-1 & Bank 2- Interviewee 1 & Bank Mobile Payment Consultant \\
B2-2 & Bank 2- Interviewee 2 & Technical Business Consultant \\
B3 & Bank 3 & Responsible for Cards and eCommerce \\
MNO1 & Mobile Network Operator 1 & Business Development Manager \\
MNO2 & Mobile Network Operator 2 & Strategy Manager \\
MNO3 & Mobile Network Operator 3 & Strategy Consultant \\
TRAVIK & TRAVIK & Sixpack Program Office Project Manager \\
C & Currence & Banking Governance Specialist \\
CS & Card Scheme & General Manager \\
PSP1 & Payment Service Provider 1 & Business Development Manager \\
PSP2 & Payment Service Provider 2 & Mobile Payment Specialist \\
MO & Merchants Organization & Manager \\
MPO1 & Mobile Payment Organization 1 & Consultant \\
MPO2 & Mobile Payment Organization 2 & Consultant \\
\hline
\end{tabular}

Table 2 List of key sources for the period after TRAVIK (2012-2016)

Data collection after the end of the TRAVIK initiative

(Selected internet sources)

\begin{tabular}{|c|c|c|c|c|}
\hline Code & $\begin{array}{l}\text { Date } \\
\text { posted }\end{array}$ & Last accessed & Source & Weblink \\
\hline \multicolumn{5}{|l|}{ Leiden initiative } \\
\hline L1 Leiden & $29-8-2013$ & $\begin{array}{l}\text { June 2016, site no } \\
\text { longer accessible } \\
\text { in } 2019\end{array}$ & Rabobank website & $\begin{array}{l}\text { https://www.rabobank.com/en/press/search/2013/mobile } \\
\text { payments.html }\end{array}$ \\
\hline Leiden L2 & $30-8-2013$ & $19-3-2019$ & YouTube video & $\begin{array}{l}\text { https://www.google.nl/url?sa=t\&rct=j\&q=\&esrc=s\&source= } \\
\text { web\&cd=2\&cad=rja\&uact=8\&ved=2ahUKEwjQzKbm5 } \\
\text { Y3hAhWDfFAKHSDPAJsQtwIwAXoECAgQAQ\&url= } \\
\text { https\%3A\%2F\%2Fwww.youtube.com\%2Fwatch\%3Fv\%3 } \\
\text { DpbwdwxI9TKc\&usg=AOvVaw0Fjc2Zv3_PiXoPN4nGAiWE }\end{array}$ \\
\hline \multicolumn{5}{|c|}{ Rabobank/ Samsung/KPN } \\
\hline Rabobank RS1 & 2015 & 19-3-2019 & Rabobank: annual report & https://www.rabobank.com/nl/images/rabobank-jaarverslag-2015.pdf \\
\hline Rabobank RS2 & 3-3-2015 & $19-3-2019$ & $\begin{array}{l}\text { Video Rabo Wallet } \\
\text { with Samsung }\end{array}$ & https://www.facebook.com/watch/?v=1035982743082740 \\
\hline Rabobank RK1 & $20-1-2016$ & 19-3-2019 & Fierce Wireless website & $\begin{array}{l}\text { http://www.fiercewireless.com/europe/story/kpn-teams-rabobank- } \\
\text { launch-android-smartphone-nfc-mobile-payment-service/2016-01-20 }\end{array}$ \\
\hline Rabobank RK2 & $19-1-2016$ & $\begin{array}{l}\text { June } 2016 \text {, site no } \\
\text { longer accessible } \\
\text { in } 2019\end{array}$ & $\begin{array}{l}\text { UL Security and } \\
\text { Identification } \\
\text { Management }\end{array}$ & $\begin{array}{l}\text { https://www.ul-ts.com/about/newsroom/ul-assists-rabobank- } \\
\text { and-kpn-in-realizing-their-joint-mobile-payment-solution/ }\end{array}$ \\
\hline \multicolumn{5}{|l|}{ VISA initiative } \\
\hline VISA V1 & $27-2-2012$ & $19-3-2019$ & VISA website & $\begin{array}{l}\text { http://investor.visa.com/news/news-details/2012/Vodafone-and- } \\
\text { Visa-Announce-Worlds-Largest-Mobile-Payments-Partnership/ } \\
\text { default.aspx }\end{array}$ \\
\hline VISA V2 & $28-2-2012$ & $19-3-2019$ & Business review & $\begin{array}{l}\text { http://www.business-review.eu/news/vodafone-and-visa-close- } \\
\text { global-partnership-for-mobile-payments-20238 }\end{array}$ \\
\hline
\end{tabular}


Open Access This article is distributed under the terms of the Creative Commons Attribution 4.0 International License (http:// creativecommons.org/licenses/by/4.0/), which permits unrestricted use, distribution, and reproduction in any medium, provided you give appropriate credit to the original author(s) and the source, provide a link to the Creative Commons license, and indicate if changes were made.

\section{References}

Allee, V. (2000). Reconfiguring the value network. Journal of Business Strategy, 21(4), 36-39.

Baland, J.-M., \& Platteau, J.-P. (1996). Halting degradation of natural resources: Is there a role for rural communities? Rome: Food \& Agriculture Org.

Benford, R. D., \& Snow, D. A. (2000). Framing processes and social movements: An overview and assessment. Annual Review of Sociology, 26, 611-639.

Blumer, H. (1969). Social movements. In McLaughlin., B. (ed.). Studies in social movements: A social psychological perspective (pp. 8-29). New York: Free Press.

Bouwman, H., de Vos, H., \& Haaker, T. (Eds.). (2008). Mobile service innovation and business models. Springer Science \& Business Media.

Campbell, J. L. (2002). Where do we stand? Common mechanisms in organizations and social movements research. Paper presented at the Social Movements and Organization Theory Conference.

Ciborra, C., \& Hanseth, O. (2000). Introduction: From control to drift. From Control to Drift. C. Ciborra (pp. 1-12). Oxford: Oxford University Press.

Constantinides, P. (2012). Perspectives and implications for the development of information infrastructures, Information Science.

Constantinides, P., \& Barrett, M. (2014). Information infrastructure development and governance as collective action. Information Systems Research, 26(1), 40-56.

Dahlberg, T., Mallat, N., Ondrus, J., \& Zmijewska, A. (2008). Past, present and future of mobile payments research: A literature review. Electronic Commerce Research and Applications, 7(2), 165-181.

Dattée, B., Alexy, O., \& Autio, E. (2018). Maneuvering in poor visibility: How firms play the ecosystem game when uncertainty is high. Academy of Management Journal, 61(2). https://doi.org/10.5465/ amj.2015.0869 .

De Reuver, M., \& Bouwman, H. (2012). Governance mechanisms for mobile service innovation in value networks. Journal of Business Research, 65(3), 347-354.

De Reuver, M., Verschuur, E., Nikayin, F., Cerpa, N., \& Bouwman, H. (2015). Collective action for mobile payment platforms: A case study on collaboration issues between banks and telecom operators. Electronic Commerce Research and Applications, 14(5), 331-344.

Eaton, B. D., Elaluf-Calderwood, S. M., \& Sorensen, C. (2010). The role of control points in determining business models for future Mobile generative systems. Paper presented at the 2010 Ninth International Conference on Mobile Business and 2010 Ninth Global Mobility Roundtable (ICMB-GMR).

Eaton, B., Elaluf-Calderwood, S., Sorensen, C., \& Yoo, Y. (2015). Distributed tuning of boundary resources: The case of Apple's iOS service system. MIS Quarterly, 39(1), 217-243.

Elaluf-Calderwood, S., Eaton, B., Herzhoff, J., \& Sorensen, C. (2011). Mobile platforms as convergent systems - Analysing control points and tussles with emergent socio-technical discourses: IntechOpen, https://doi.org/10.5772/27225 .
Fichman, R. G., Santos, B. L. D., \& Zheng, Z. (2014). Digital innovation as a fundamental and powerful concept in information systems curriculum. MIS Quarterly, 38(2), 329-353.

Goffman, E. (1974). Frame analysis: An essay on the Organization of Experience. Cambridge: Harvard University Press.

Gregor, S. (2006). The nature of theory in information systems. Management Information Systems Quarterly, 30(3), 611-642.

Hargrave, T. I., \& van de Ven, A. H. (2006). A collective action model of institutional innovation. Academy of Management Review, 31(4), 864-888.

Henningsson, S., \& Henriksen, H. Z. (2011). Inscription of behaviour and flexible interpretation in information infrastructures: The case of European e-customs. Journal of Strategic Information Systems, 20(4), 355-372.

Hess, T., \& Constantiou, I. (2018). Introduction to the special issue on "digitalization and the media industry". Electronic Markets, 28(1), 77-78.

Jacobides, M. G., Cennamo, C., \& Gawer, A. (2018). Towards a theory of ecosystems. Strategic Management Journal, 39(8), 2255-2276.

Kaplan, S. (2008). Framing contests: Strategy making under uncertainty. Organization Science, 19(5), 729-752.

Klein, H. K., \& Myers, M. D. (1999). A set of principles for conducting and evaluating interpretive field studies in information systems. MIS Quarterly, 23(1), 67-93.

Klein, S., Schellhammer, S., (2011). Developing IOIS as collective action: A cross- country comparison in the health care sector, System Sciences (HICSS), 2011.

Kling, R., \& Iacono, S. (1998). The mobilization of support for computerization: The role of computerization movements. Social Problems, 35(3), 226-243.

Kollock, P. (1998). Social dilemmas: The anatomy of cooperation. Annual Review of Sociology, 24, 183-214.

Lusch, R. F., Nambisan, S. (2015). Service Innovation: A ServiceDominant Logic Perspective, MIS Quarterly, 31 (1), 155-175.

Markus, L. M., \& Robey, D. (1988). Information technology and organizational change: Causal structure in theory and research. Management Science, 34(5), 583-598.

Markus, M. L., Steinfield, C. W., Wigand, R. T., \& Minton, G. (2006). Industry-wide information systems standardization as collective action: The case of the U.S. residential mortgage industry. MIS Quarterly, 30, 439-465.

Monge, P. R., Fulk, J., Kalman, M., Flanagin, A., Parnassa, C., \& Rumsey, S. (1998). Production of collective action in alliancebased interorganizational communication and information systems. Organization Science, 9, 411-433.

Monteiro, E., Pollock, N., \& Williams, R. (2014). Innovation in Information Infrastructures: Introduction to the Special Issue. Journal of the Association for Information Systems, 15(4), i-iii.

Nikayin, F., De Reuver, M., \& Itälä, T. (2013). Collective action for a common service platform for independent living services. International Journal of Medical Informatics, 82(10), 922-939.

Olson, M. (1965). The logic of collective action. Cambridge: Harvard University Press.

Ondrus, J., \& Pigneur, Y. (2007). Cross-industry preferences for development of Mobile payments in Switzerland. Electronic Markets, 17(2), 142-152. https://doi.org/10.1080/10196780701296386.

Orlikowski, W. J., \& Baroudi, J. J. (1991). Studying information technology in organizations: Research approaches and assumptions. Information Systems Research, 2(1), 1-28.

Ostrom, E. (2000). Collective action and the evolution of social norms. Journal of Economic Perspectives, 14(3), 137-158.

Ozcan, P., \& Santos, F. M. (2015). The market that never was: Turf wars and failed alliances in mobile payments. Strategic Management Journal, 36(10), 1486-1512.

Pagani. (2013). Digital business strategy and value creation: Framing the dynamic cycle of control points. MIS Quarterly, 37(2), 617-632. 
Peltoniemi, M., \& Vuori, E. (2004). Business ecosystem as the new approach to complex adaptive business environments. In Proceedings of eBusiness research forum, 2, 267-281.

Pettigrew, A. M. (1985). Contextualist research: A natural way to link theory and practice. In E. E. Lawler (Ed.), Doing research that is useful in theory and practice (pp. 222-273). San Francisco: Jossey Bass.

Pettigrew, A. M. (1987). Context and action in the transformation of the firm. Journal of Management Studies, 24(6), 649-670.

Pettigrew, A. M. (1990). Longitudinal field research on change: Theory and practice. Organization Science, 1(3), 267-292.

Pettigrew, A. M., Woodman, R. W., \& Cameron, K. S. (2001). Studying organizational change and development: Challenges for future research. Academy of Management Journal, 44(4), 697-713.

Rukanova, B., Henriksen, H. Z., Raesfeld, A. von, Stijn, E. van, Tan, Y.H. (2008). A Collective Action Perspective on Technological Innovation in Business/ Government Networks. ECIS, In Proceedings of the EIS (2008). Available online at: https://aisel. aisnet.org/cgi $/$ viewcontent.cgi? article $=1009 \&$ context $=$ eis 2008 . Accessed 4 June 2019

Rukanova, B., Henriksen, H. Z., van Stijn, E., and Tan, Y.H. (2009): Bringing IS innovation in a highly-regulated environment: a collective action perspective. Research Memorandum 2009, Vrije Universiteit Amsterdam. Available online at: ftp://ftp.repec.org/ opt/ReDIF/RePEc/vua/wpaper/pdf/20090012.pdf.

Rukanova, B., Henningsson, S., Henriksen, H.Z., Tan, Y.H. (2018). Digital Trade Infrastructures: A Framework for Analysis. Complex Systems Informatics and Modeling Quarterly, 14, 1-21.

Salisbury, R. H. (1969). An exchange theory of interest groups. Midwest Journal of Political Science, 13, 1-32. https://doi.org/10.2307/ 2110212 .

Sanner, T. A., Manda, T. D., \& Nielsen, P. (2014). Grafting: Balancing control and cultivation in information infrastructure innovation. Journal of the Association for Information Systems, 15(4), 220-243.

Star, S. L. (1999). The ethnography of infrastructure. American Behavioral Scientist, 43(3), 377-391.

Storbacka, K., Brodie, R. J., Böhmann, T., Maglio, P. P., \& Nenonen, S. (2016). Actor engagement as a microfoundation for value co-creation. Journal of Business Research, 69(8), 3008-3017.

Streeck, W. (1990). Interest heterogeneity and organizing capacity: Two class logics of collective action, Estudios/Working Papers (Centro de Estudios Avanzados en Ciencias Sociales), vol. 2.
Tilson, D., Lyytinen, K., \& Sørensen, C. (2010). Research commentary digital infrastructures: The missing IS research agenda. Information Systems Research, 21(4), 748-759.

Van de Ven (2005). Running in packs to develop knowledge-intensive technologies. MIS Quarterly, 29 (2), Special Issue on Information Technologies and Knowledge Management, 365-377.

Van Stijn, E., Rukanova, B.; Wensley, A., Tan, Y.H. (2009). Moving an eInnovation from a living lab to the real world: Politically savvy framing in ITAIDE's beer living lab" BLED 2009 Proceedings. Paper 31. http://aisel.aisnet.org/bled2009/31. Accessed 4 June 2019

Vargo, S. L., \& Lusch, R. F. (2008). Service dominant logic: Continuing the evolution. Journal of the Academy of Marketing Science, 36(1), $1-10$.

Vargo, S. L., Maglio, P. P., \& Akaka, M. A. (2008). On value and value co-creation: A service systems and service logic perspective. European Management Journal, 26(3), 145-152.

Walsham, G. (1993). Interpreting information systems in organizations. Chichester: Wiley.

Walsham, G. (1995). Interpretive case studies in IS research: Nature and method. European Journal of Information Systems, 4(2), 74-81.

Walsham, G. (2006). Doing interpretive research. European Journal of Information Systems, 15(3), 320-330.

Walter, J., Kellermanns, F. W., \& Lechner, C. (2012). Decision making within and between organizations rationality, politics, and alliance performance. Journal of Management, 38(5), 1582-1610.

Witell, L., Snyder, H., Gustafsson, A., Fombelle, P., \& Kristensson, P. (2015). Defining service innovation: A review and synthesis. Journal of Business Research, 69, 2863-2872. https://doi.org/10. 1016/j.jbusres.2015.12.055

Yoo, Y., Henfridsson, O., \& Lyytinen, K. (2010). Research commentarythe new organizing logic of digital innovation: An agenda for information systems research. Information Systems Research, 21(4), 724-735.

Yoo, Y., Boland, R. J., Jr., Lyytinen, K., \& Majchrzak, A. (2012). Organizing for innovation in the digitized world. Organization Science., 23, 1398-1408.

Publisher's note Springer Nature remains neutral with regard to jurisdictional claims in published maps and institutional affiliations. 